\title{
Two perspectives on the coupled carbon, water and energy exchange in the planetary boundary layer
}

\author{
M. Combe ${ }^{1}$, J. Vilà-Guerau de Arellano ${ }^{1}$, H. G. Ouwersloot ${ }^{2}$, C. M. J. Jacobs ${ }^{3}$, and W. Peters ${ }^{1,4}$ \\ ${ }^{1}$ Department of Meteorology and Air Quality, Wageningen University, Wageningen, the Netherlands \\ ${ }^{2}$ Max Planck Institute for Chemistry, Mainz, Germany \\ ${ }^{3}$ Climate change and adaptive land and water management, Alterra Wageningen UR, Wageningen, the Netherlands \\ ${ }^{4}$ Centre for Isotope Research, Groningen University, Groningen, the Netherlands \\ Correspondence to: M. Combe (marie.combe@wur.nl)
}

Received: 14 March 2014 - Revised: 21 November 2014 - Accepted: 24 November 2014 - Published: 8 January 2015

\begin{abstract}
Understanding the interactions between the land surface and the atmosphere is key to modelling boundarylayer meteorology and cloud formation, as well as carbon cycling and crop yield. In this study we explore these interactions in the exchange of water, heat and $\mathrm{CO}_{2}$ in a croplandatmosphere system at the diurnal and local scale. To that end, we couple an atmospheric mixed-layer model (MXL) to two land-surface schemes developed from two different perspectives: while one land-surface scheme $\left(A-g_{s}\right)$ simulates vegetation from an atmospheric point of view, the other (GECROS) simulates vegetation from a carbon-storage point of view. We calculate surface fluxes of heat, moisture and carbon, as well as the resulting atmospheric state and boundarylayer dynamics, over a maize field in the Netherlands, on a day for which we have a rich set of observations available. Particular emphasis is placed on understanding the role of upper-atmosphere conditions like subsidence in comparison to the role of surface forcings like soil moisture. We show that the atmospheric-oriented model (MXL-A-gs $)$ outperforms the carbon storage-oriented model (MXL-GECROS) on this diurnal scale. We find this performance is partly due to the difference of scales at which the models were made to run. Most importantly, this performance strongly depends on the sensitivity of the modelled stomatal conductance to water stress, which is implemented differently in each model. This sensitivity also influences the magnitude of the surface fluxes of $\mathrm{CO}_{2}$, water and heat (surface control) and subsequently impacts the boundary-layer growth and entrainment fluxes (upper atmosphere control), which alter the atmospheric state. These findings suggest that observed $\mathrm{CO}_{2}$ mole fractions in the boundary layer can reflect strong influ-
\end{abstract}

ences of both the surface and upper-atmosphere conditions, and the interpretation of $\mathrm{CO}_{2}$ mole fraction variations depends on the assumed land-surface coupling. We illustrate this with a sensitivity analysis where high subsidence and soil moisture depletion, typical for periods of drought, have competing and opposite effects on the boundary-layer height $h$. The resulting net decrease in $h$ induces a change of $12 \mathrm{ppm}$ in the late-afternoon $\mathrm{CO}_{2}$ mole fraction. Also, the effect of such high subsidence and soil moisture depletion on the surface Bowen ratio are of the same magnitude. Thus, correctly including such two-way land-surface interactions on the diurnal scale can potentially improve our understanding and interpretation of observed variations in atmospheric $\mathrm{CO}_{2}$, as well as improve crop yield forecasts by better describing the water loss and carbon gain.

\section{Introduction}

The land surface and atmosphere interact on many time scales, and understanding their exchange of energy, water, carbon and chemical tracers is key to many research fields, including climate modelling (Cox et al., 2013; Sitch et al., 2008), crop yield prediction (Lobell et al., 2011), hydrology (Teuling et al., 2010), atmospheric composition (Bonan, 2008) and meteorology (Vilà-Guerau de Arellano et al., 2012). When the interaction concerns a vegetated surface and the planetary boundary layer overhead, the cycles of carbon, water and energy are strongly coupled, notably at the surface. Responding to their environment, plants regulate the exchange of $\mathrm{CO}_{2}$ and water vapour through the opening and 
closing of their stomata (Jarvis, 1976; Cowan, 1978; Ball, 1988), which in turn impacts the energy partitioning at the surface. This plant control over the carbon, water and energy exchange plays a key role, especially in climate change studies, which is why the current generation of climate models all include mechanisms to describe the stomatal response of vegetation to changing environmental conditions (Farquhar et al., 1982; Collatz et al., 1991; Leuning et al., 1995; Jacobs et al., 1996). The ongoing rise of temperature and $\mathrm{CO}_{2}$ concentration are already shown to affect the coupled cycles of water and carbon as plants have become more efficient in water use over the past decades (Keenan et al., 2013; Brienen et al., 2011; Silva and Horwath, 2013). Quantitative understanding of these interactions between plants and the atmosphere is therefore needed.

The development of numerical models to describe landatmosphere interactions is based on two perspectives. While vegetation models focus on carbon accumulation in landsurface types, such as forests and crops, and treat the atmosphere as a prescribed upper boundary condition, the atmospheric models focus on weather forecast and use land surface as a prescribed lower boundary condition. The former group includes (dynamic) vegetation models and crop yield models such as LPJ (Sitch et al., 2003), ORCHIDEESTICS (Smith et al., 2010) and CERES-maize (Bert et al., 2007). The latter includes submodels of numerical weather prediction systems and atmospheric transport models such as in SiBcrop-RAMS (Corbin et al., 2010), RAMS-Leaf3-5PM (Tolk et al., 2009) and WRF-VPRM (Ahmadov et al., 2007). The next generation of vegetation and atmospheric models integrates both perspectives by allowing two-way interactions between the land and the atmosphere. In these models, carbon from the atmosphere is accumulated into vegetation, which in turn feeds back energy, water and $\mathrm{CO}_{2}$ into the atmosphere overhead (e.g. the $\mathrm{C}^{4}$ MIP models HadCM3LC, IPSL-CM4-LOOP, Bern-CC in Cox et al., 2013; Friedlingstein et al., 2006).

Recent studies have analysed the underlying mechanisms of land-atmosphere interactions and feedbacks using twoway couplings between the land surface and the planetary boundary layer (Santanello et al., 2013; Mcgrath-Spangler and Denning, 2010; van Heerwaarden et al., 2009). Among them, Vilà-Guerau de Arellano et al. (2012) have clearly demonstrated the importance of how these interactions are described. They showed that future conditions of $\mathrm{CO}_{2}$ level rise and warming would influence the boundary-layer cloudiness by affecting the plant stomatal aperture and vapour pressure deficit (VPD), thus changing both evapotranspiration and atmospheric humidity. Upper-atmosphere conditions, which are connected to large-scale synoptic weather patterns, were suggested to further affect the stomatal response through their control of the daytime boundary-layer growth and entrainment. Although the Vilà-Guerau de Arellano et al. study only focused on the diurnal and local scale with a relatively simple coupled model, the implications for two-way coupled models operating on much larger and longer scales were evident.

In this study, we continue this approach and analyse the coupling between the heat, moisture and carbon cycles for a maize field. We specifically focus on the diurnal scale, like Vilà-Guerau de Arellano et al. (2012), paying particular attention to the simulation of carbon fluxes and especially photosynthesis, which have a cumulative impact on crop growth and crop yield at the seasonal scale. We also explore the relative importance of upper-atmosphere conditions like subsidence, compared to the role of surface forcings like soil moisture, for the determination of $\mathrm{CO}_{2}$ mole fractions. We choose to focus on crop-atmosphere interactions because croplands occupy a fifth of the European Union land surface (FAOSTAT 2011 land-use statistics), are important for food production and yet are often not well represented in land-surface models. In dynamic global vegetation models (DGVM) and soil-vegetation-atmosphere transfer models (SVAT models), they are conceptualised either as natural (e.g. Sitch et al., 2003) or managed grass (e.g. Krinner et al., 2005) and only distinguished by $\mathrm{C}_{3}$ or $\mathrm{C}_{4}$ plant photosynthesis. Differences between species of crops in development are often not simulated but rather are prescribed using seasonal leaf area index (LAI). Also, nitrogen stress or the effect of management options (fertilisation, irrigation, ploughing) are often not implemented at all, although they have been shown to have a large impact on crop carbon cycling (Ciais et al., 2010; Lehuger et al., 2010; Gervois et al., 2008). In contrast to DGVMs, process-based crop models could potentially better represent these crop characteristics (Challinor et al., 2009; Betts, 2005).

In order to investigate the differences between the generic and specialised representation of crop biology, we use a process-based crop yield forecast model, the genotype-by-environment interaction on crop growth simulator (GECROS; Yin and van Laar, 2005), and a more meteorological-oriented, surface-atmosphere exchange model, A-g (Ronda et al., 2001). We couple them to the same atmospheric mixed-layer model (MXL) and compare their ability to reproduce crop-atmosphere interactions. Both models simulate the daytime carbon, water and heat surface fluxes, with A-g $\mathrm{g}_{\mathrm{s}}$ more focussed on representing the individual surface energy balance terms. The additional levels of complexity embedded in GECROS are the separation of the effects of diffuse and direct radiation on photosynthesis, the internal calculation of crop LAI, the allocation and storage of carbon into crop organs (leading to crop yield) and the interaction of the carbon and nitrogen cycles (nitrogen stress). We assess both models using a very comprehensive observational data set from a maize field in the Netherlands (Jans et al., 2010) that includes atmospheric variables (temperature, humidity, radiation), the surface fluxes of $\mathrm{CO}_{2}$, water and (sensible and ground) heat, the soil temperature and humidity and the seasonal crop development (crop height, LAI, dry matter weight). We combine it with boundary-layer 
height data from a nearby meteorological station (Cabauw experimental site for atmospheric research, online database available at http://www.cesar-database.nl). It is important to stress that these observations were conducted at the same local scale as we simulate (field scale), which is smaller than typically simulated in climate models (i.e. $50 \mathrm{~km}$ resolution at minimum). In order to bridge these different scales (Eitzinger et al., 2008; Betts, 2005), we couple both our surface models, GECROS and A- $\mathrm{g}_{\mathrm{s}}$, to a model for the atmospheric boundary layer (ABL). This framework enables us to draw conclusions about the key boundary-layer-vegetation interactions, and we use it to answer two research questions:

1. What are the essential processes at the surface and upper atmosphere governing the coupled carbon, water and energy budgets in the daytime crop-atmosphere system?

2. Which modelling perspective can best reproduce these essential processes, and what does it teach us about the level of complexity needed in a daytime diurnal landsurface scheme?

We hypothesise that:

1. In addition to surface processes, entrainment and subsidence are essential processes which determine the carbon, water and energy budgets of the daytime cropatmosphere system.

2. MXL-GECROS can best reproduce the daytime cropatmosphere interactions because of the higher level of crop biology detail embedded in the model.

The next section presents a description of our surface and atmospheric models as well as of their coupling strategy. We then present our findings with the full daytime intercomparison of our two coupled models against observations and a sensitivity analysis of the two-way daytime cropatmosphere interactions.

\section{Methods}

\subsection{Observations}

In order to verify the behaviour of the cropland-atmosphere system, we use a comprehensive set of surface exchange, atmosphere, soil and crop growth observations, which were performed in 2007 and 2008 in a maize field located in Wageningen, the Netherlands (see Jans et al., 2010). This data set consists of half-hourly averages of the sensible and latent heat fluxes and $\mathrm{CO}_{2}$ exchange, obtained with the eddy covariance (EC) technique. They are quality-controlled according to the protocols described in Aubinet et al. (2012). These EC observations are supported by various continuous micrometeorological measurements in the air and in the soil. In addition to the continuous measurements, this data

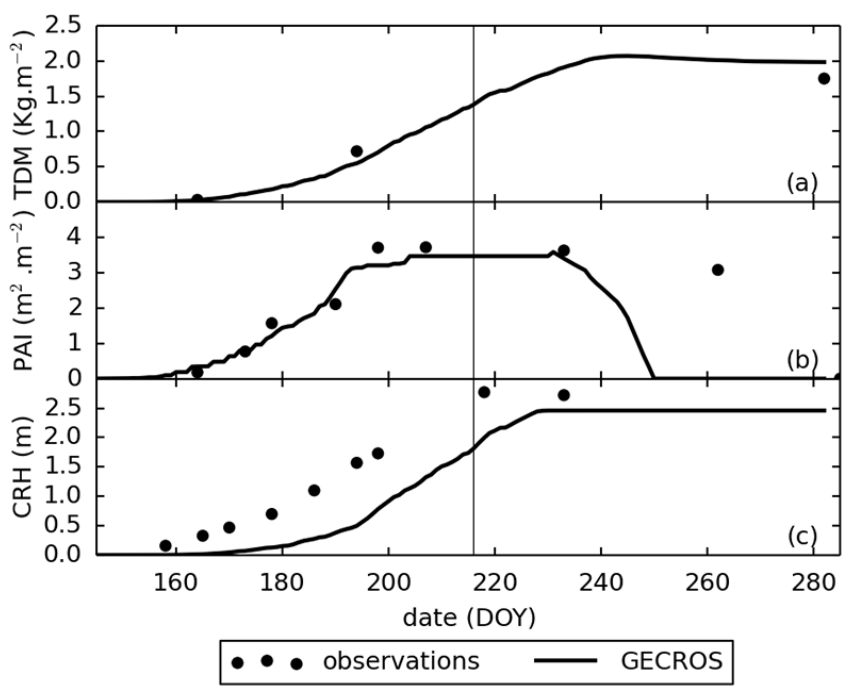

Figure 1. Seasonal evolution of the (a) maize total dry matter (TDM), (b) plant area index (PAI) and (c) crop height (CRH), from sowing to maturity dates. The vertical continuous line represents 4 August 2007, the date at which we dynamically couple both the MXL-GECROS and MXL-A-g models (see the assessment of these couplings in Sect. 3.1).

set includes soil type, crop management data and intermittent observations of crop height, plant area index (PAI; i.e. a proxy for LAI) and the dry weight of crop organs over the growing season. To complete the atmospheric observations from Jans et al., we use the boundary-layer height from the wind profiler measurements of the closest meteorological station (Cabauw, the Netherlands) located approximately 50 kmwest from the maize site (Cabauw experimental site for atmospheric research, online database available at http://www.cesar-database.nl). In the absence of boundarylayer height data for Wageningen, this is the best estimation possible.

Because we want to focus on the diurnal scale to study the interactions and feedbacks of our maize-atmosphere system, we specifically pick 1 day of observations, 4 August 2007: a sunny, cloudless day with a convective atmospheric boundary layer above the maize field. We pick that specific date because our atmospheric boundary-layer model can only reproduce well-mixed boundary layers and we want to avoid sensitive periods of emergence and senescence times for the crop. On 4 August 2007 our maize crop is in the reproductive stage, at the peak of its growth (see PAI in Fig. 1).

On 4 August 2007, the continuous measurements show a daytime energy gap of $19 \%$ between the net absorbed radiation and the sum of the surface (latent, sensible and ground) heat fluxes. This energy gap is typical for a crop like maize, mainly due to heat storage (Meyers and Hollinger, 2004). The gap can also be partially generated by photosynthesis, which can proceed at unusually large rates for maize, largescale heat transport processes and measurement accuracy 
(Foken et al., 2010; Foken, 2008). Since the two surface schemes we use assume the closure of the surface energy budget, we allocate the missing energy (or residual) into extra sensible and latent heat in the observations, using the Bowen ratio to determine the partitioning (see Eq. 1).

Flux $_{\text {corrected }}=$ Flux $_{\text {observed }}+$ Residual $\times f$,

with $f= \begin{cases}\frac{\beta}{1+\beta} & \text { for SH } \\ \frac{1}{1+\beta} & \text { for LE }\end{cases}$

This method ensures the observed Bowen ratio is conserved after correction. It has been previously used by Barbaro et al. (2014), Foken (2008), Twine et al. (2000) and Beljaars and Bosveld (1997). For reference, we show in Fig. 3 both the observed and corrected fluxes. Note that the corrected fluxes are used in the further model comparisons.

\subsection{Models}

In order to study the daytime cropland-atmosphere system, we couple two surface schemes, GECROS and A-g $\mathrm{g}_{\mathrm{s}}$, to a convective atmospheric boundary-layer scheme, MXL, and analyse their behaviour compared to our observations on 4 August 2007.

\subsubsection{MXL, a convective atmospheric boundary-layer scheme}

Our atmospheric boundary-layer scheme is a box model, which describes accurately the development of the daytime atmospheric boundary layer when turbulence is strong (mixed-layer situation). The first studies to develop the concept of a mixed-layer model where done by Lilly (1968), Betts (1973), Carson (1973) and Tennekes (1973). The version used in this paper has been described by Vilá-Guerau de Arellano et al. (2009). The ABL is well mixed during this strongly convective daytime regime, and thus we infer that the instantaneous atmospheric variables assume a single value throughout the whole ABL. The top of the boundary layer is characterized by potential temperature, moisture and $\mathrm{CO}_{2}$ inversions, simplified as sudden "jumps" or gradients, which sharply separate the ABL state from the free tropospheric profiles. The evolution of the ABL state and height over time is determined by boundary fluxes (surface, entrainment and advection) of heat, moisture and $\mathrm{CO}_{2}$. Entrainment fluxes are calculated. The MXL model has been widely tested and is a robust model for sunny days with few to no boundary-layer clouds - all conditions met on 4 August 2007 over our maize field.

\subsubsection{GECROS, a crop yield forecast model}

GECROS is a land-surface model specialised in crop carbon storage (i.e. a crop yield forecast model). We use version 1.0, which was released by Yin and van Laar (2005). GECROS is from the two-big-leaf family of models initiated by De Pury and Farquhar (1997), which means the crop canopy is simplified into two leaves, each possessing one substomatal cavity. One leaf represents the entire sunlit leaf area of the canopy, the other represents the entire shaded leaf area; their proportions evolve with crop age and solar angle. The two big leaves work in parallel for daytime photosynthetic and transpiration processes. This enables different efficiencies of photosynthesis to happen under diffuse and direct radiation.

On the diurnal scale, GECROS is a crop growth model based on evaporative demand, which means that the potential photosynthesis is first calculated according to the amount of available photosynthetically active radiation, and then it determines the leaf conductance and the potential transpiration. The actual photosynthesis and transpiration are obtained by evaluating the soil water content: if the available soil moisture is higher than the amount of water needed for potential transpiration, GECROS works at full potential. Otherwise, GECROS transpires solely the available water supply and reduces its photosynthesis and stomatal conductance accordingly. In addition to water stress, GECROS has a nitrogen cycle implemented that interacts with the carbon cycle, accounting for nitrogen stress. This last feature did not play a role in our study of crop-atmosphere interactions on $4 \mathrm{Au}-$ gust 2007.

On the seasonal scale, GECROS simulates its own phenological development based on the accumulation of heat (i.e. growing degree-days). Also, it accumulates carbon into the different crop organs (leaves, stems, roots and storage organs), which determines crop yield. Both of these features, typical of a crop model but not of a DGVM or SVAT model, allow interactions and feedbacks between the crop and the atmosphere to change with crop ageing. This is a potential advantage for a seasonal study of the cropland-atmosphere system.

\subsubsection{Modifications to GECROS used in this paper and validation}

We analysed the surface energy budget of GECROS and identified two core problems in its original version: (a) the budget of net long-wave radiation was faulty, generating too much outgoing long-wave radiation and consequently too little energy was retained at the surface; and (b) the calculated VPD was too high because it used the humidity at $2 \mathrm{~m}$ instead of inside-canopy humidity, stimulating too much latent heat at the expense of sensible heat. In order for GECROS to have realistic heat fluxes to feed to the MXL model, we implemented the following changes to improve its surface energy balance. 
Table 1. Seasonal statistics of the daily integrated Qnet, LE, SH and NEE from Fig. 2. Statistics are computed from sowing to maturity dates. We present the observed and modelled means and standard deviations, the root mean squared error (RMSE) between the model and the observations (in the same units as the mean) and the $R^{2}$ between the model and the observations. Note that the large error on NEE is partly due to the inability of the model to reproduce the LAI after DOY 240 (see Fig. 1).

\begin{tabular}{lcccccc}
\hline Variable [units] & \multicolumn{2}{c}{ Observed } & \multicolumn{2}{c}{ Modelled } & RMSE & \multirow{2}{*}{$R^{2}$} \\
& mean & stddev & mean & stddev & & \\
\hline Qnet $\left[\mathrm{MJ} \mathrm{m}^{-2}\right.$ ] & 8.9 & 3.7 & 8.1 & 4.4 & 1.4 & 0.95 \\
$\mathrm{LE}\left[\mathrm{MJ} \mathrm{m}^{-2}\right]$ & 5.9 & 2.5 & 5.5 & 3.5 & 1.8 & 0.75 \\
$\mathrm{SH}\left[\mathrm{MJ} \mathrm{m}^{-2}\right]$ & 1.7 & 1.3 & 1.8 & 1.7 & 1.1 & 0.59 \\
NEE $\left[\mathrm{g} \mathrm{CO}_{2} \mathrm{~m}^{-2}\right]$ & -15.8 & 19.5 & -19.1 & 28.8 & 16.0 & 0.74 \\
\hline
\end{tabular}

First we replaced the original net long-wave radiation budget with a simplified multilayer budget:

$\mathrm{LW}_{i}=(\underbrace{\mathcal{E}_{\mathrm{ATMOS}} \times \sigma \times T_{\mathrm{ATMOS}}^{4}}_{\text {Incoming radiation }}-\underbrace{\mathcal{E}_{i} \times \sigma \times T_{i}^{4}}_{\text {Outgoing radiation }}) \times F_{i}$,

with $F_{i}= \begin{cases}f_{\mathrm{veg}} & \text { if sunlit leaf }(i=1) \\ 0 & \text { if shaded leaf }(i=2) \\ 1-f_{\mathrm{veg}} & \text { if bare soil }(i=3),\end{cases}$

where $\mathcal{E}_{\mathrm{ATMOS}}$ and $\mathcal{E}_{i}$ are emissivities, $T_{\mathrm{ATMOS}}$ and $T_{i}$ are temperatures, $\sigma$ is the Stefan-Boltzmann constant and $f_{\text {veg }}$ is the vegetation-cover fraction. We assume similar blackbody radiation $\left(\mathcal{E}_{1}=\mathcal{E}_{2}=\mathcal{E}_{3}=1\right.$ ) originating from the sunlit leaf, shaded leaf and the underlying soil. As a consequence, we approximate the net long-wave radiation budget of the shaded leaf to be zero. Note that there is no interaction of long-wave radiation between the bare soil and vegetated fractions and thus no reabsorption of emitted long-wave radiation. This approximation for shaded leaves in a multilayer model is supported by Zhao and Qualls (2006).

Then, in order to decrease the allocation of energy into the latent heat flux, we create a ground heat flux (it was assumed negligible in the original GECROS version). We take a firstorder estimate and parameterize it to be $10 \%$ of the net absorbed radiation at the surface (this assumption was validated for short grass by de Bruin and Holtslag, 1982). Finally, we implement a vapour pressure profile in the canopy layer to enable a more realistic description of VPD. In our implementation, the vapour pressure $(e)$ changes linearly from the top to the bottom of the canopy and from the actual vapour pressure at $2 \mathrm{~m}$ to the saturation vapour pressure at $2 \mathrm{~m}$. The state of saturation at the bottom of the canopy is adjusted for cases of lighter vegetation cover. This allows the vapour pressure at the bottom always to be larger or equal to $e(2 \mathrm{~m})$.

$e(z)=e(2 \mathrm{~m})+\left(e_{0}-e(2 \mathrm{~m})\right) \times d_{\mathrm{rel}}$,

with $e_{0}=e(2 \mathrm{~m})+\left(e_{\mathrm{SAT}}(2 \mathrm{~m})-e(2 \mathrm{~m})\right) \times f_{\mathrm{veg}}$.

We use the relative canopy depth $d_{\text {rel }}=0.5$ for shaded leaves and $d_{\text {rel }}=0.9$ for the soil. Note that, in contrast to the canopy profile for vapour pressure, we do not implement a canopy profile for air temperature. We keep air temperature vertically constant and equal to the $2 \mathrm{~m}$ air temperature. We refer to the modified version of the GECROS model from here on.

In order to validate our modified version of GECROS, we performed a standard simulation of the maize growth for our location and year of interest (2007) and compared our results to observations. The initial conditions for this experiment are presented in Table A3. In Fig. 1 we show three cumulative variables evolving over the growing season: yield, PAI and crop height. In Fig. 1a we find that the GECROS model reproduces the observed maize yield at day 282 within $10 \%\left(2 \mathrm{~kg} \mathrm{~m}^{-2}\right.$ simulated vs. $1.8 \mathrm{~kg} \mathrm{~m}^{-2}$ observed), indicating a correct integration of the net primary production (NPP) over the growing season. Moreover, Fig. $1 \mathrm{~b}$ and $\mathrm{c}$ show that GECROS also approaches the observed maximum PAI and crop height, with a $3.5 \mathrm{~m}^{2} \mathrm{~m}^{-2}$ PAI and a $2.5 \mathrm{~m}$ height vs. an observed $3.8 \mathrm{~m}^{2} \mathrm{~m}^{-2}$ PAI and $2.8 \mathrm{~m}$ height. This suggests that NPP was also assigned to the correct GECROS carbon pools (stems, leaves, roots) during crop development. This satisfactory agreement for carbon storage was expected and is reassuring since the GECROS model was built as a crop yield model (Yin and van Laar, 2005).

In addition, we show in Fig. 2 the seasonal evolution of surface available energy (Qnet), latent heat flux (LE), sensible heat flux $(\mathrm{SH})$ and net $\mathrm{CO}_{2}$ exchange (i.e. net ecosystem exchange; NEE) in daily integrated amounts. Their seasonal means, presented in Table 1 , are all in agreement with the observations, except for a small overestimation of the mean NEE. This overestimation could be due to a too-low soil respiration. Also, the $R^{2}$ between the modelled and observed daily integrated Qnet (0.95) is very high, and the $R^{2}$ for the daily integrated LE (0.75), SH (0.59) and NEE (0.74) are satisfactory. The high degree to which GECROS reproduces the variability from day to day results from the prescribed meteorological driver data in the seasonal simulation, which provides the model with observed radiation, atmospheric temperature and precipitation data. Note that the mismatch between observations and GECROS on individual days can nevertheless be quite large (cf. the RMSE compared to the observed seasonal means and standard deviations in Table 1) 
despite the improvements we made to its energy balance. Such a mismatch could be produced by the incorrect simulation of key driver variables (e.g. Qnet and soil moisture) in GECROS, by the absence of a diurnal-scale weather forcing (only one data input is given per day) or even by the lack of atmospheric feedback. This partly reinforces the aim of our study, which is to focus on understanding the daytime two-way crop-atmosphere interactions.

\subsubsection{A-g , a land-surface exchange model}

The A-g $\mathrm{g}_{\mathrm{s}}$ model is a generic meteorological-oriented landsurface model, which was originally published by Jacobs et al. (1996). Its use has been validated for grapevine (Jacobs et al., 1996), $C_{3}$ grass, $C_{4}$ grass and soybean (Ronda et al., 2001). It is a single-big-leaf model that relates plant $\mathrm{CO}_{2}$ assimilation to the stomatal conductance $\left(g_{\mathrm{s}}=1 / r_{\mathrm{s}}\right)$ via a $\mathrm{CO}_{2}$ gradient (see Eq. 5). We use the version of Ronda et al. (2001), where the impact of soil water depletion on $g_{\mathrm{s}}$ is calculated with a linear function from wilting point to field capacity. In A-g $g_{s}$, the upscaled canopy conductance $\left(g_{c}\right)$ is hence calculated as a function of light, temperature, stomata to atmospheric $\mathrm{CO}_{2}$ concentration ratio, VPD, soil water stress and LAI. In Eq. (5), soil respiration is computed with an Arrhenius-type equation, using the concepts of reference respiration $R_{10}$ and of the activation energy for chemical reactions $E_{\mathrm{a}}$. In addition to the $\mathrm{CO}_{2}$ fluxes, A-g calculates surface fluxes of latent and sensible heat with the same conductance approach (see Eqs. 6-7). Finally, the ground heat flux is calculated as the thermal diffusivity of the skin layer times the temperature difference between the soil and skin layers.

$$
\begin{aligned}
& \underbrace{\left(\overline{w^{\prime} c^{\prime}}\right)_{\mathrm{s}}}_{\begin{array}{c}
\text { Net ecosystem } \\
\text { exchange }
\end{array}}=\overbrace{\underbrace{\left(\frac{1}{r_{\mathrm{a}}+1.6 r_{\mathrm{s}}}\right)}_{\mathrm{CO}_{2} \text { conductance }} \times \underbrace{\left(c_{\text {stomata }}-c_{\mathrm{atmos}}\right)}_{\mathrm{CO}_{2} \text { gradient }}}^{\text {Net primary production }} \\
& \text { + Soil Respiration } \\
& \underbrace{\left(\overline{w^{\prime} q^{\prime}}\right)_{\mathrm{s}}}_{\begin{array}{c}
\text { Surface } \\
\text { moisture flux }
\end{array}}=\underbrace{\left.\left(f_{\text {veg }} \times \frac{1}{r_{\mathrm{a}}+r_{\mathrm{s}}}+f_{\text {veg }}\right) \times \frac{1}{r_{\mathrm{a}}+r_{\text {soil }}}\right)}_{\begin{array}{c}
\text { water conductance } \\
\times \underbrace{\left(q_{\text {sat }}\left(T_{\text {skin }}\right)-q_{\text {atmos }}\right)}_{\text {moisture gradient }}
\end{array}} \\
& \underbrace{\left(\overline{w^{\prime} \theta^{\prime}}\right)_{\mathrm{s}}}_{\begin{array}{c}
\text { Surface } \\
\text { heat flux }
\end{array}}=\underbrace{\left(\frac{1}{r_{\mathrm{a}}}\right)}_{\text {heat conductance }} \times \underbrace{\left(T_{\text {skin }}-\theta_{\text {atmos }}\right)}_{\text {temperature gradient }}
\end{aligned}
$$

$\mathrm{A}-\mathrm{g}_{\mathrm{s}}$ adapts its surface fluxes according to the vegetation cover and LAI but simulates neither its own crop phenological development nor carbon accumulation into crop organs. This set-up makes the $\mathrm{A}-\mathrm{g}_{\mathrm{s}}$ model, in the present version, suited for the simulation of surface exchange at the diurnal scale only.

\subsection{Simulation setup}

With the three models presented before, we make two couplings to study the daytime maize-atmosphere system: MXL-A-g and MXL-GECROS. We design them as two-way couplings: the surface fluxes given by $\mathrm{A}-\mathrm{g}_{\mathrm{s}}$ and GECROS are used as surface conditions for the MXL model, and in return, the incoming short-wave radiation, atmospheric temperature, humidity, wind speed and $\mathrm{CO}_{2}$ mole fraction are fed to the surface schemes as environmental conditions. The internal calculations of MXL are done on a time step of $1 \mathrm{~min}$. In addition, $\mathrm{A}-\mathrm{g}_{\mathrm{s}}$ and GECROS feed the surface fluxes to MXL with a frequency of 1 and 5 min respectively. Note that we have checked and validated that the 4 min difference in communication frequency does not affect the coupling. Finally, all calculations start at 06:00 UTC, after sunrise when turbulent convection is already active, and last until 18:00 UTC, thus ensuring the atmosphere is well mixed during that time.

The main settings of our models are presented in Tables A1-A3. For MXL-GECROS, we first initialise the uncoupled GECROS model with the maize parameters of Yin and van Laar (2005) and Sinclair and de Wit (1975) (cf. Table A3). The uncoupled GECROS model is run from emergence date to 4 August 2007 in order to obtain all initial conditions of its internal variables on the coupling date. On 4 August, we initialise all our coupled models following the available soil, crop and atmospheric observations from Jans et al. (2010). Note that we prescribe horizontal heat and moisture advection during the first hours of our numerical experiments to improve the match to observations during the early-morning transition to convective conditions. In addition, we use the $\mathrm{C}_{4}$ photosynthesis parameters published by Ronda et al. (2001) for the $\mathrm{A}-\mathrm{g}_{\mathrm{s}}$ scheme.

The data set from Jans et al. (2010) provides the soil volumetric water content on 4 August 2007, but in absence of measurements of the soil wilting point and field capacity we assume typical values for these quantities for our soil type. In light of the uncertainty of the soil moisture measurements and of these soil moisture characteristic points, we decide to adjust the modelled soil volumetric water content to obtain a Bowen ratio similar to the observed one. We perform this adjustment with the two models. The soil moisture index (SMI, see Eq. 8) obtained with MXL-GECROS is very low, which suggests a heavy drought situation that was not observed:

$\mathrm{SMI}=\frac{W_{\text {actual }}-W_{\text {wilting point }}}{W_{\text {field capacity }}-W_{\text {wilting point }}}$,

with $W$ the soil volumetric water content.

In consequence, we decide to apply the SMI obtained with MXL-A-g $(55.5 \%)$ in both cases. In the end, both models operate with the same soil type and SMI (see Appendix Tables A2 and A3) but yield different Bowen ratios and surface energy balances because of their difference in water-stress implementation. 


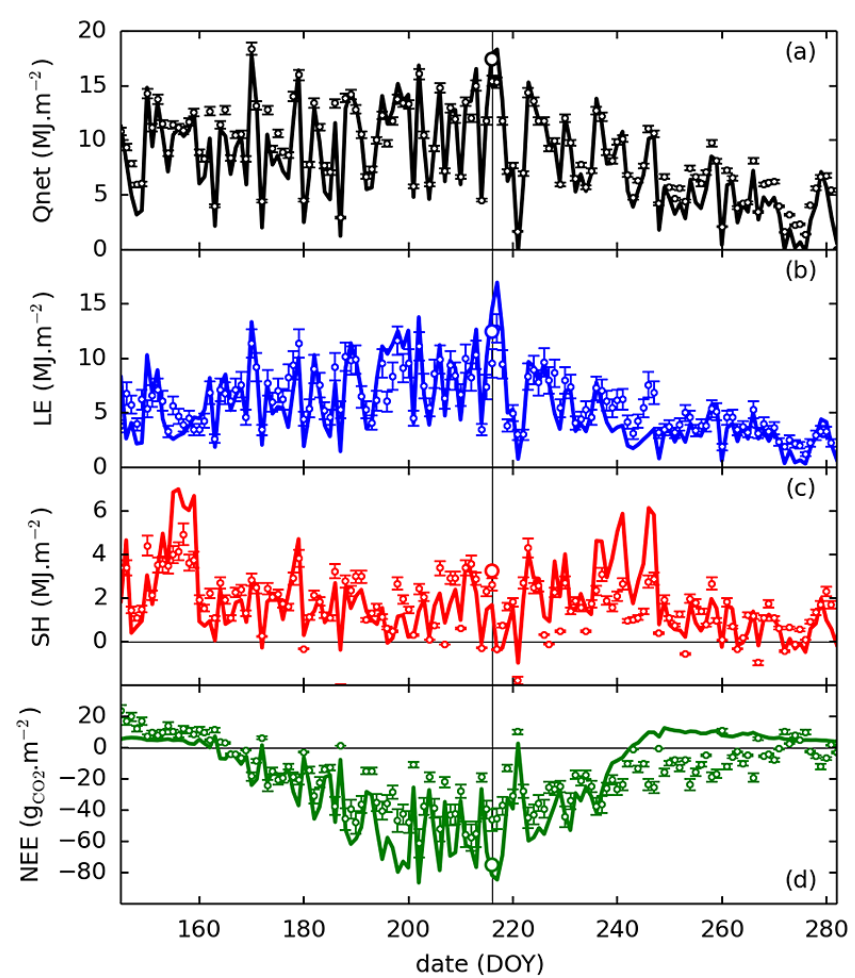

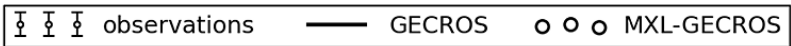

Figure 2. Daily integrated (a) net radiation (Qnet), (b) latent heat flux (LE), (c) sensible heat flux (SH) and (d) net ecosystem exchange (NEE) at the maize site, from sowing to maturity dates. The integration is computed each day, using the average daytime flux times the daytime number of seconds. Days with more than $20 \%$ measurement gaps are discarded. Errors are computed as a direct sum of the eddy covariance random errors for instantaneous fluxes, which are presented in Sect. 4.4 of Aubinet et al. (2012). The vertical continuous line represents 4 August 2007, the date at which we dynamically couple both the MXL-GECROS and MXL-A-g models (see the assessment of these couplings in Sect. 3.1).

In the absence of observations for soil respiration on 4 August 2007, we adjust the MXL-A-g goil respiration to be identical to the internally calculated value from MXL-GECROS $\left(0.2 \mathrm{mg} \mathrm{CO}_{2} \mathrm{~m}^{-2} \mathrm{~s}^{-1}\right.$ at 12:00 UTC). This means that for NEE, the only difference between the two models is in their representation of NPP. We execute this by setting the reference respiration $R_{10}$ of MXL-A-g $\mathrm{g}_{\mathrm{s}}$ at $0.03 \mathrm{mg} \mathrm{CO}_{2} \mathrm{~m}^{-2} \mathrm{~s}^{-1}$, a low but realistic number when considering the natural range of variation of $R_{10}$ in the Netherlands (cf. Jacobs et al., 2007). Also, the estimate of soil respiration is in the range of observed values at that period of the year (Jans et al., 2010).

Finally, in order to obtain the same input of short-wave radiation as in our observations $\left(25.0 \mathrm{MJ} \mathrm{m}^{-2}\right)$ on $4 \mathrm{Au}-$ gust 2007 , we prescribe a cloud cover of $22.5 \%$ in our models to match the observed total incoming short-wave radia-
Table 2. Daytime integrals of Qnet, LE, SH and NEE from Fig. 3, calculated from 08:00 to 18:00 UTC on 4 August 2007.

\begin{tabular}{lcccc}
\hline & $\begin{array}{c}\text { Qnet } \\
{\left[\mathrm{MJ} \mathrm{m}^{-2}\right]}\end{array}$ & $\begin{array}{c}\mathrm{LE} \\
{\left[\mathrm{MJ} \mathrm{m}^{-2}\right]}\end{array}$ & $\begin{array}{c}\mathrm{SH} \\
{\left[\mathrm{MJ} \mathrm{m}^{-2}\right]}\end{array}$ & $\begin{array}{c}\mathrm{NEE} \\
{\left[\mathrm{g} \mathrm{CO}_{2} \mathrm{~m}^{-2}\right]}\end{array}$ \\
\hline Observations & 14.4 & 9.7 & 3.4 & -52.0 \\
MXL-A-gs & 13.1 & 8.2 & 4.2 & -41.4 \\
MXL-GECROS & 15.3 & 11.8 & 2.1 & -65.0 \\
\hline
\end{tabular}

tion (SWin) during daytime. This is because the observations show a significant reduction of SWin compared to the output of astronomic functions for a cloudless day, likely due to haze or fog in the morning. With our two coupled models, we make an intercomparison of their simulations against observations to study the ability of these couplings to reproduce the cropland-atmosphere interactions.

\subsection{Sensitivity analysis}

Related to our first research question, we perform a sensitivity analysis of the daytime cropland-atmosphere system to upper-atmosphere conditions (subsidence) in comparison to surface conditions (soil moisture). We conduct this sensitivity analysis with the model that shows the best performance on the diurnal scale (i.e. MXL-A-g , see Results). We design two study cases, stemming from the control case of $4 \mathrm{Au}$ gust 2007 (Sect. 2.3), by selecting two drivers to modify separately: (a) the "high-subsidence" case, where we replace the very small horizontal wind divergence $\left(7 \times 10^{-6} \mathrm{~s}^{-1}\right)$ of the control case by a high one $\left(4 \times 10^{-5} \mathrm{~s}^{-1}\right)$, representing a realistic case of strong subsidence in the Netherlands; and (b) the "soil moisture depletion" case, where we apply a reduction of soil moisture (from 0.110 to $0.105 \mathrm{~cm}^{3} \mathrm{~cm}^{-3}$ ) equivalent to a $5 \%$ decrease of SMI for that soil type. A decrease of $5 \%$ SMI could happen over several days in a drying phase (e.g. Daly et al., 2004; Betts, 2004). We analyse the impact of these two external forcings on the daytime surface energy balance and NEE, as well as the net effect on the atmospheric $\mathrm{CO}_{2}$ mole fraction.

\section{Results}

\subsection{Intercomparison of coupled models against observations}

\subsubsection{Daytime evolution of the surface fluxes}

Figure 3 presents three of the four components of the surface energy balance, together with the net surface $\mathrm{CO}_{2}$ exchange, for 4 August 2007. We identify three phases in the observed surface fluxes daytime diurnal cycle. Phase A corresponds to the early-morning transition from a stable to a convective boundary layer. During Phase A, the SH flux switches from negative to positive (see Fig. 3b), and this heat becomes the 


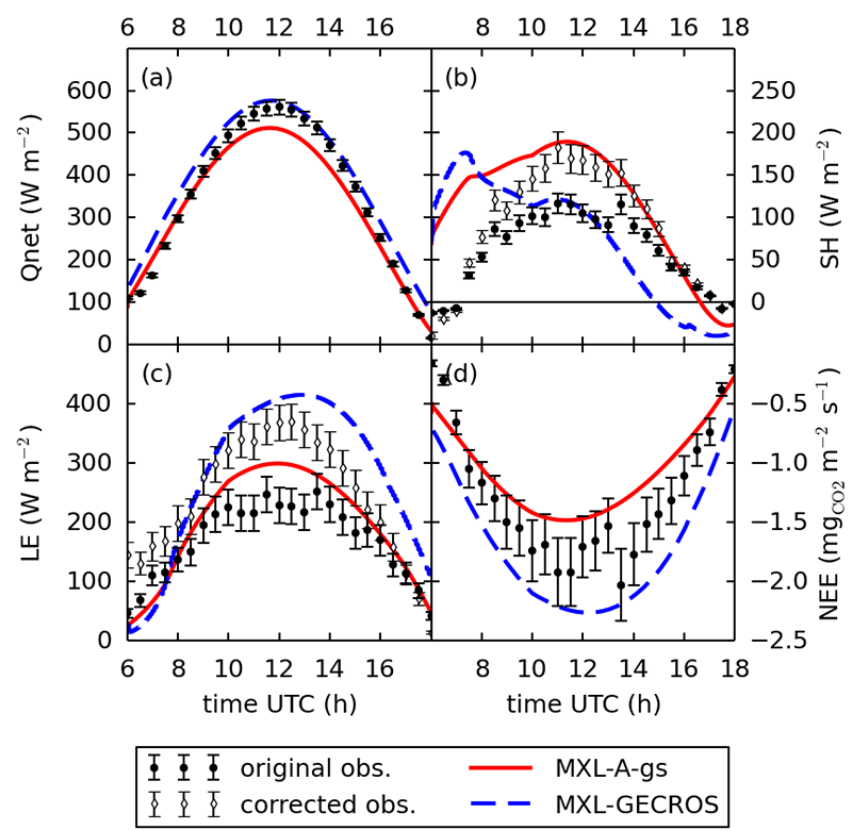

Figure 3. Daytime diurnal cycle of the (a) net radiation (Qnet), (b) sensible heat flux (SH), (c) latent heat flux (LE) and (d) net ecosystem exchange (NEE) on 4 August 2007. For comparison with the models we corrected the observations to allocate the residual of the surface energy balance into extra SH and LE (see Sect. 2.1). The error bars represent the average eddy covariance random errors of Aubinet et al. (2012, see Sect. 4.4). NEE is negative when $\mathrm{CO}_{2}$ is being removed from the atmosphere. Differences in NEE between the two couplings directly reflect differences in net plant photosynthesis, as soil respiration is identical between the two models.

source of convection which works to break up the thermal stratification built during night-time. Reproducing this observed transition with our models is difficult: firstly because advection of heat and moisture plays an important role in this early-morning phase (see next section) and secondly because dew on the vegetation possibly delayed the onset of a positive $\mathrm{SH}$ in observations. In addition, when $\mathrm{SH}$ is negative, the corrected observed LE flux assumes unrealistically high values (see Fig. 3c) due to our correction method. For all these reasons we will exclude the early-morning transition from our model evaluation.

Phase B is the most important part of the day, when fluxes are highest and convection is dominant. During Phase B, MXL-GECROS strongly underestimates the Bowen ratio, with an underestimated SH in accordance with its consistently higher LE flux. As a consequence and due to the coupling with evapotranspiration, photosynthesis is overestimated, as shown in NEE (considering that the soil respiration is low and identical between MXL-GECROS and MXL$\left.A-g_{s}\right)$. These strong fluxes contribute most to the daily integrated amount, which impacts the atmospheric state. Therefore it is very important to calculate correct surface fluxes during Phase B, which MXL-A-g $\mathrm{g}_{\mathrm{s}}$ does slightly better than MXL-GECROS.

Finally, Phase $\mathrm{C}$ is the late-afternoon transition from a convective to a stable boundary layer. During Phase $\mathrm{C}$, the $\mathrm{SH}$ flux changes from positive to negative, causing the convection to cease. Also, evapotranspiration and photosynthesis decrease until fluxes become negligible. The late-afternoon transition for SH occurs much earlier for MXL-GECROS (15:00 UTC) than for MXL-A-g $\mathrm{g}_{\mathrm{s}}$ (16:45 UTC) and the observations (17:15 UTC), which means the assumption of a convective boundary layer, the basis of the MXL model, ends earlier for MXL-GECROS than for MXL-A-gs .

Overall, Fig. 3 shows that both MXL-GECROS and MXLA- $\mathrm{g}_{\mathrm{s}}$ calculate reasonable magnitudes and temporal evolutions of the surface fluxes for the observed maize crop, but MXL-A-g $g_{s}$ performs slightly better than MXL-GECROS. We find in Fig. 3a that both models calculate different amounts of Qnet. They benefit from the same amount of incoming short-wave radiation $\left(25.0 \mathrm{MJ} \mathrm{m}^{-2}\right.$ integrated over the day) but yield different radiation balances, since they have differently parameterized functions for albedo and longwave radiation budgets of the leaves and soil. As a result, a different amount of available energy will be partitioned into sensible heat, latent heat and ground heat fluxes. Following Qnet, in Fig. 3b-d we find that, integrated between 08:00 and 18:00 UTC, MXL-GECROS underestimates SH by a total of $1.3 \mathrm{MJ} \mathrm{m}^{-2}(38 \%)$ and overestimates LE by $2.1 \mathrm{MJ} \mathrm{m}^{-2}$ (22\%) and NEE by $13.0 \mathrm{~g} \mathrm{CO}_{2} \mathrm{~m}^{-2}(25 \%$, see Table 2$)$. On the other hand, MXL-A-g $\mathrm{g}_{\mathrm{s}}$ overestimates $\mathrm{SH}$ by a total of $0.8 \mathrm{MJ} \mathrm{m}^{-2}(24 \%)$, and underestimates LE by $1.5 \mathrm{MJ} \mathrm{m}^{-2}$ $(15 \%)$ and $\mathrm{NEE}$ by $10.6 \mathrm{~g} \mathrm{CO}_{2} \mathrm{~m}^{-2}(20 \%)$. Considering the three fluxes of heat, water and $\mathrm{CO}_{2}$, we find that MXL-A$\mathrm{g}_{\mathrm{s}}$ reproduces the observed daytime evolution of the surface fluxes better than MXL-GECROS on 4 August 2007. It is important to remember that we prescribe the initial soil moisture to match the observed Bowen ratio with MXL-A-g $\mathrm{g}_{\mathrm{s}}$, which is why we arrive at this better fit for the surface energy balance of this model. We prescribe the same SMI (55.5\%) to both models, which have different water-stress responses and are thus the lesser fit for MXL-GECROS. To see how the differences in magnitudes and timing of heat, water and carbon surface fluxes impact the atmospheric state, we assess the atmospheric mixed layer next.

\subsubsection{Daytime evolution of the ABL}

Figure 4 shows that MXL-A-g s $_{s}$ outperforms MXL-GECROS when simulating a fully coupled atmosphere. When comparing observations with the model results, note that we present the modelled mixed-layer (or bulk) values against the $2 \mathrm{~m}$ observations for temperature and specific humidity. Considering the general properties of the surface layer (a gradual decrease of temperature and humidity from the surface level to the mixed-layer level), the observed $2 \mathrm{~m}$ atmosphere is thus expected to be slightly warmer and moister than the 


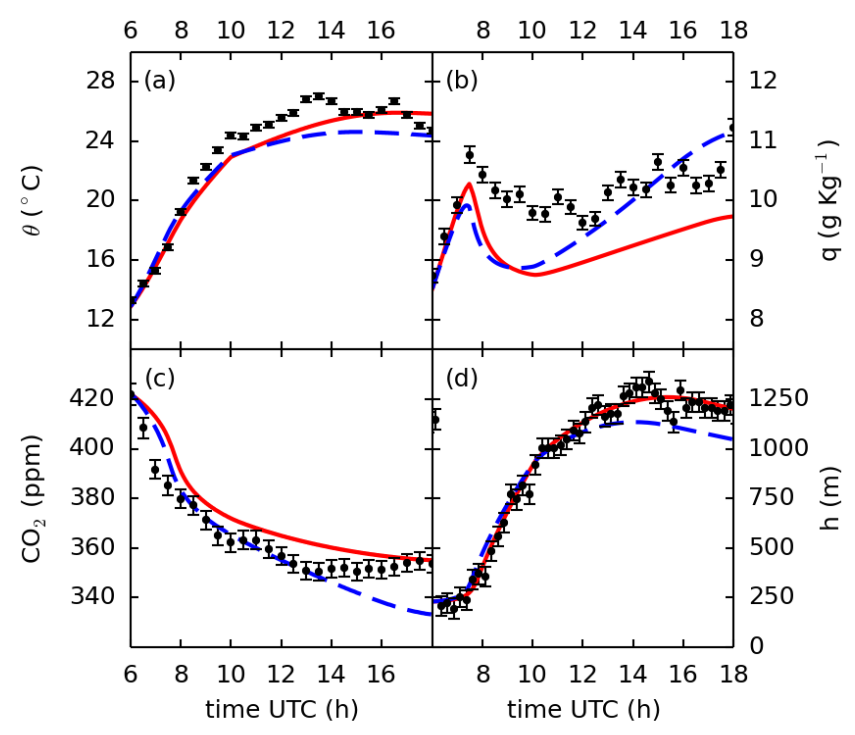

I $\Phi$ observations $\longrightarrow$ MXL-A-gs -- MXL-GECROS

Figure 4. Daytime diurnal cycle of (a) the potential temperature $\theta$, (b) the specific humidity $q$, (c) the $\mathrm{CO}_{2}$ mole fraction and (d) the boundary-layer height $h$ at the maize site on 4 August 2007. The errors for the $\theta, q$ and $\mathrm{CO}_{2}$ measurements are obtained based on the factory specifications of the instruments. The error for $h$ is assumed to be constant and equal to $50 \mathrm{~m}$ (personal communication, Henk Klein Baltink). Note that, in order to reproduce the early-morning temperature and humidity variations, we prescribed advection of heat until 10:00 UTC and advection of humidity until 07:30 UTC (see settings in Table A1).

modelled mixed-layer atmosphere. Also, because the negative SH depletes the layer of air close to the surface from heat at the very end of the day, the observed $2 \mathrm{~m}$ temperature is expected to decrease at that time. Keeping these expected differences in mind, we find that the MXL-A-g model reproduces the observed temperature and moisture values well, while MXL-GECROS calculates a clearly toohigh 18:00 UTC humidity $\left(11.2 \mathrm{~g} \mathrm{~kg}^{-1}\right)$ compared to the observations $\left(9.8 \mathrm{~g} \mathrm{~kg}^{-1}\right)$. Similarly, MXL-GECROS simulates a too $\mathrm{CO}_{2}$-depleted atmosphere $(-20 \mathrm{ppm})$ and a too-shallow boundary layer $(-250 \mathrm{~m})$ compared to observations, where MXL-A-gs performs relatively well.

When we relate the integrated heat, water and $\mathrm{CO}_{2}$ surface fluxes of Table 2 to the atmosphere of Fig. 4, we observe, as expected, that a lower integrated amount of SH in MXLGECROS compared to MXL-A-gs leads to a $2{ }^{\circ} \mathrm{C}$ lower maximum temperature $\left(24\right.$ instead of $\left.26^{\circ} \mathrm{C}\right)$. Also, a higher integrated LE in MXL-GECROS compared to MXL-A-gs results in a $1.4 \mathrm{~g} \mathrm{~kg}^{-1}$ higher specific humidity at the end of the day (11.1 instead of $9.7 \mathrm{~g} \mathrm{~kg}^{-1}$ ). Finally, a lower integrated NEE in MXL-GECROS compared to MXL-A-g leads to a $22 \mathrm{ppm}$ lower $\mathrm{CO}_{2}$ mole fraction ( 333 instead of $355 \mathrm{ppm}$ ). However, when we compare the modelled and observed atmosphere we find discrepancies. This is because surface fluxes do not directly translate into a daytime evolution of the atmospheric temperature, humidity and $\mathrm{CO}_{2}$ mole fraction. For instance, in Fig. 4c we find that the daytime overestimation of NEE by MXL-GECROS leads to a too strongly $\mathrm{CO}_{2}$ depleted atmosphere compared to observations only in the afternoon. Also, despite a daytime underestimated NEE, MXL-A-g $\mathrm{g}_{\mathrm{s}}$ reproduces satisfactorily the observed $\mathrm{CO}_{2}$ daily minimum on 4 August 2007. This shows that errors in the surface fluxes can be cancelled by other non-local effects like the advection, entrainment or boundary-layer dilution (e.g. see the role of dry-air entrainment in van Heerwaarden et al., 2009, or $\mathrm{CO}_{2}$ advection in Casso-Torralba et al., 2008). A full analysis of the daytime diurnal cycle of the atmosphere must thus include the contribution of these processes.

Advection fluxes can change the expected evolution of the atmosphere. The occurrence of heat and moisture advection on 4 August 2007 is noticeable because the observed daytime range in temperature and the early-morning increase in humidity are too large to be solely due to realistic crop-sensible heat and evapotranspiration fluxes. We thus prescribed horizontal heat and moisture advection during the first hours of our numerical experiments (see Table A1). We estimate the contribution of advection for the MXL-A-g $\mathrm{g}_{\mathrm{s}}$ model to the daytime temperature range (DTR, $13{ }^{\circ} \mathrm{C}$ ) to be $3{ }^{\circ} \mathrm{C}$ and the contribution to the early-morning specific humidity increase $\left(1.8 \mathrm{~g} \mathrm{~kg}^{-1}\right)$ to be $1.2 \mathrm{~g} \mathrm{~kg}^{-1}$. The observed $\mathrm{CO}_{2}$ mole fraction stabilisation and increase after 13:00 UTC is also most probably generated by advection because an increase in $\mathrm{CO}_{2}$ mole fraction could only be due to (a) a positive NEE (which we do not have), (b) strong entrainment of $\mathrm{CO}_{2}$-rich air (which is unlikely at the end of the day) or (c) $\mathrm{CO}_{2}$ advection. Despite this observation, we prescribed no advection of $\mathrm{CO}_{2}$ in our model runs to more clearly demonstrate the role of surface fluxes in the $\mathrm{CO}_{2}$ budget.

Finally, entrainment fluxes also alter the state of the boundary layer. The boundary-layer height $(h)$ of Fig. $4 \mathrm{~d}$ can serve as a proxy for measuring the amount of warmer, drier, $\mathrm{CO}_{2}$-depleted air that is entrained from the free troposphere into the boundary layer in cases where there is no or very little subsidence (our case). In the end, we find in Fig. 4d that both models calculate a maximum $h$ that is lower $(-150 \mathrm{~m}$ for MXL-A-g and $-250 \mathrm{~m}$ for MXL-GECROS) than observed $(1400 \mathrm{~m})$. Differences between the models are due to differences in heat input from SH and the subsequent entrainment, since the heat advection, free tropospheric vertical profiles and subsidence are identical between the models. However, in reality there must be discrepancies in all of these variables to create the existing differences between models and observations. Clearly, both boundary-layer dynamics and surface fluxes must be included in atmospheric simulations to properly capture the contribution of the largescale air masses to the local atmospheric state. We will investigate the relevance of upper-atmosphere conditions in more detail in the next section. 


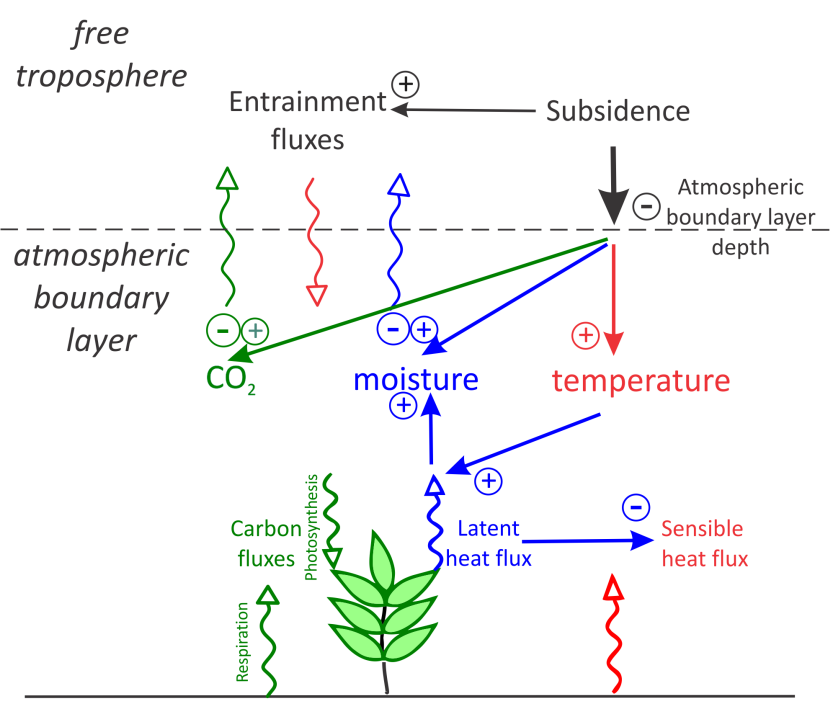

land

Figure 5. Interactions between the carbon (green), water (blue) and heat (red) cycles in the coupled land-ABL system. Increased subsidence tends to reduce the boundary-layer height, which directly causes the $\mathrm{ABL}$ to warm up, dry and become $\mathrm{CO}_{2}$-depleted. This in turn affects the land-surface, which feeds back on the ABL by shifting its Bowen ratio towards more evapotranspiration.

\subsection{Sensitivity analysis of an upper-atmosphere forcing}

We show in the previous sections that MXL-A-g $\mathrm{g}_{\mathrm{s}}$ performs best to reproduce the daytime diurnal crop-atmosphere coupling on 4 August 2007. As a consequence, we use it to conduct a sensitivity experiment. Our goal here is to quantify the strength of the couplings between the upper atmosphere, the boundary layer and the crop surface. From now on, we refer to the MXL-A-g $\mathrm{g}_{\mathrm{s}}$ run of the previous sections as the control run, from which we derive our sensitivity analysis runs. We design two case studies: one where we apply a stronger upper-atmosphere forcing (high subsidence) and another where we alter a land-surface forcing (depletion of soil moisture, see Sect. 2.4 for a detailed specification of the settings). Both high subsidence and soil moisture depletion are characteristic of a drought period. Figure 5 presents the main interactions between carbon, water and energy that result in the state of the land-atmosphere. We use it to summarise the changes linked to increased subsidence, discussed in the next paragraphs.

While the high-subsidence case stimulates the latent heat flux LE through the warming of the boundary layer (red arrows in Fig. 5), the soil moisture depletion case decreases LE through the closure of plant stomata. Subsidence is a largescale forcing that counteracts the growth of the boundary layer and even reduces $h$ once its growth has stopped (see the high-subsidence case in Fig. 6a). It enhances the entrainment of warm free tropospheric air and causes a smaller volume of air to be warmed up by the same surface sensible heat

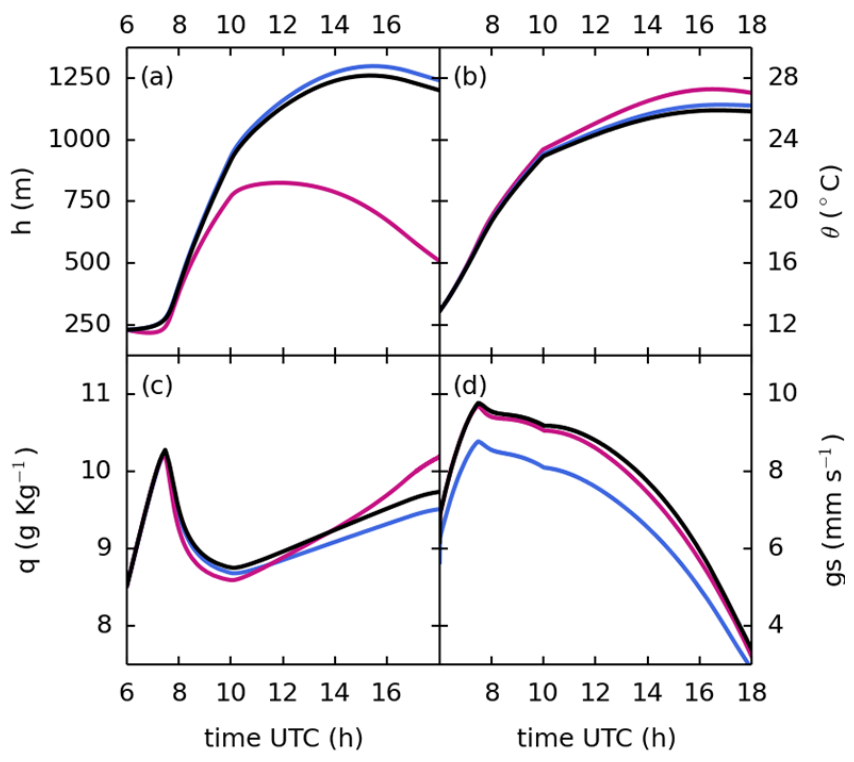

$\longrightarrow$ control $\longrightarrow$ high subsidence $\longrightarrow-5 \%$ smi

Figure 6. Boundary layer and surface response to high subsidence and soil moisture depletion. High subsidence, an upper-atmosphere forcing, directly impacts the boundary-layer height $h$ and affects the specific humidity $q$ and the potential temperature $\theta$. This contrasts with soil moisture depletion, a surface forcing, which acts through the stomatal conductance $g_{\mathrm{s}}$ to impact the evapotranspiration and $q$.

flux, thus increasing the atmospheric temperature $\left(+1.5^{\circ} \mathrm{C}\right.$ at 18:00 UTC, see Fig. 6b). This warming of the atmosphere increases the VPD at the surface $(+0.2 \mathrm{kPa}$ at 14:00 UTC, not shown here) and shifts the evaporative fraction $(\mathrm{EF}=$ $\mathrm{LE} /(\mathrm{SH}+\mathrm{LE}))$ towards evapotranspiration by $5 \%$ on average during the day (see Fig. 7a). Finally, this increase in LE results in a moistening of the atmosphere that counteracts the initial atmospheric drying caused by a short-term enhancement of dry-air entrainment (not shown here). In Fig. 6c we find that the specific humidity, which is first lower than in the control run, becomes higher than in the control run after 14:00 UTC due to the stimulation of LE.

On the other hand, for the lower soil moisture case, the decreased availability of soil moisture generates a decrease in surface conductance $g_{\mathrm{s}}$ on average by $1 \mathrm{~mm} \mathrm{~s}^{-1}$ during the day (see Fig. 6d). This decrease in surface conductance leads to a reduction of EF of $5 \%$ throughout the day (see Fig. 7a) and finally to a reduction of $h$ of $40 \mathrm{~m}$ (see Fig. 6a). As a result, we find that both cases affect the energy partitioning at the surface with equivalent magnitude. It is thus important to consider both the effect of high subsidence and of soil moisture depletion on evapotranspiration in the context of drought response. Moreover, it is interesting to analyse how the net surface carbon uptake is affected by them.

High subsidence and soil moisture depletion have different impacts on the net $\mathrm{CO}_{2}$ flux at the surface. While the high-subsidence case shows no difference in photosynthesis 


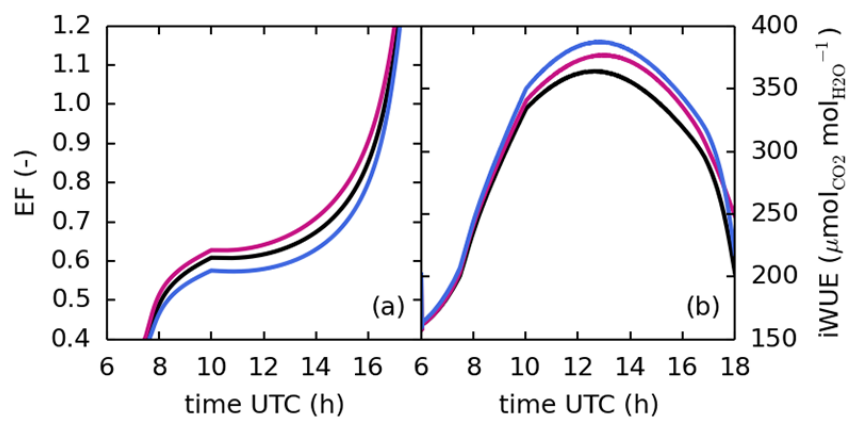

$\begin{array}{lllll}- & & & \text { control } & -5 \% \text { smi }\end{array}$

Figure 7. The response of surface exchange to high subsidence and soil moisture depletion. High subsidence and soil moisture depletion both shift the evaporative fraction $(\mathrm{EF}=\mathrm{LE} /(\mathrm{SH}+\mathrm{LE}))$ by $5 \%$ on average, and both increase the intrinsic water use efficiency $\left(\mathrm{iWUE}=\mathrm{NPP} / g_{\mathrm{s}}\right)$ by 3 and $6 \%$ respectively on average, as a result of two different mechanisms (respectively an increase of VPD and a stomata closure).

and respiration compared to the control case, the reduced soil moisture case presents a reduction in photosynthesis $\left(-0.2 \mathrm{mgCO}_{2} \mathrm{~m}^{-2} \mathrm{~s}^{-1}\right.$ at midday in Fig. 9a). This is because while the reduced soil moisture case generates a clear stomata closure in response to water stress $\left(-1 \mathrm{~mm} \mathrm{~s}^{-1}\right.$ at 14:00 UTC in Fig. 6d), the high-subsidence case generates only a slight change of stomata opening in response to the increased VPD $\left(-0.3 \mathrm{~mm} \mathrm{~s}^{-1}\right.$ at 14:00 UTC in Fig. 6d), which is entirely compensated by a slight increase in the surface $\mathrm{CO}_{2}$ gradient (+8 ppm at 14:00 UTC, not shown here). Thus, as a result of two very different feedback mechanisms on net photosynthesis and evapotranspiration (see previous paragraph), we obtain an increase in intrinsic water-use efficiency (iWUE $=\mathrm{NPP} / \mathrm{g}_{\mathrm{s}}$ ) of 11 and $18 \mu \mathrm{molCO}_{2} \mathrm{~mol} \mathrm{H}_{2} \mathrm{O}^{-1}$ for the high-subsidence and soil moisture depletion cases respectively compared to the control case (i.e. +3 and $+6 \%$ on average, see Fig. 7b). This means both forcings make plant carbon exchange, and by extension plant carbon storage, slightly more water efficient. While a reduction in soil moisture has an immediate impact on the daily crop yield (integrated decrease of NPP of $1.2 \mathrm{~g} \mathrm{C} \mathrm{m}^{-2}$ ), high subsidence does not. However, high subsidence worsens soil moisture depletion $(-1 \% \mathrm{SMI})$ because it increases $\mathrm{EF}$ by $5 \%$, as we described earlier. This suggests that subsidence could ultimately contribute to a yield decrease if the drought situation is prolonged. It is therefore interesting to extend our sensitivity analysis to a larger range of SMI and subsidence in order to verify the response of the system.

We perform a more detailed sensitivity analysis of iWUE and EF to soil moisture and subsidence, which is presented in Fig. 8. We start our 10201 experiments with identical initial conditions to the control case (point $\mathrm{C}$ in Fig. 8), except that we vary both the initial SMI by $20 \%$ (on $x$ axis) and

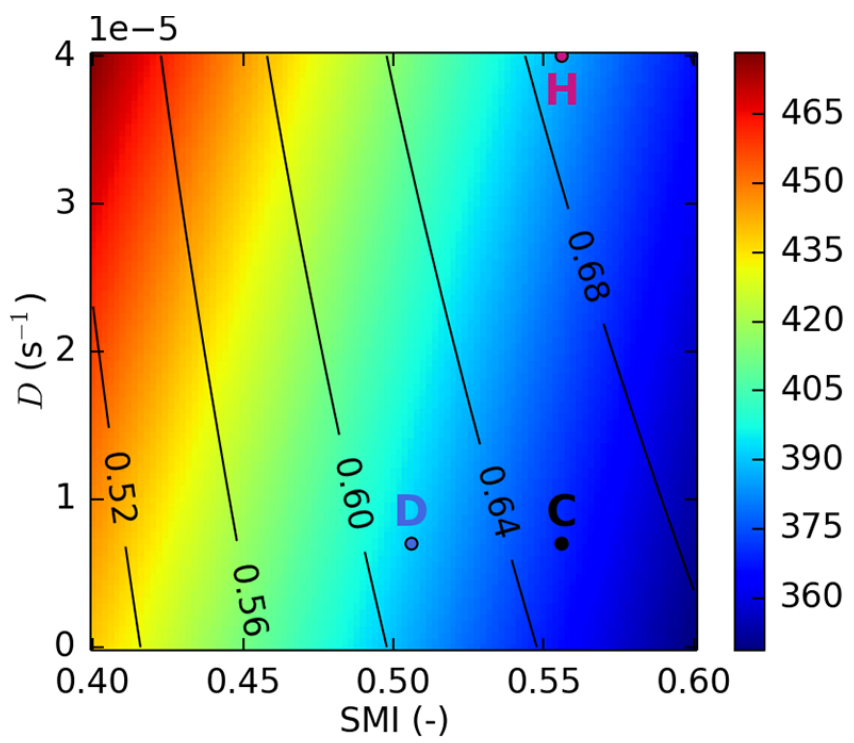

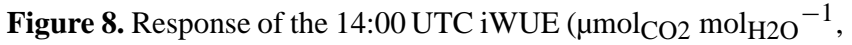
in colours) and EF (unitless, in contours) to seasonal variations of SMI and the large-scale divergence $(D)$. Scatter points represent the control case (C), the dry ( $-5 \%$ SMI) case (D) and the highsubsidence case $(\mathrm{H})$ of Figs. 6 and 7.

the large-scale divergence by $4 \times 10^{-5} \mathrm{~s}^{-1}$ ( $D$, on $y$ axis). Note that the variable $D$ is related to the subsidence velocity $\left(w_{\mathrm{s}}\right)$ through the $\mathrm{ABL}$ height $\left(w_{\mathrm{s}}=-D \times h\right)$. Thus, the full range of $D$ explored in Fig. 8 represents a subsidence velocity of 0 to $0.04 \mathrm{~m} \mathrm{~s}^{-1}$, the maximum being typical of stationary high-pressure systems. By studying these ranges, we cover small fluctuations of drivers around the control case as well as conditions associated with drought (i.e. much dryer soil with high subsidence). Figure 8 shows that EF and iWUE are more dependent on changes in SMI than variations of $D$. However, note that day-to-day changes in SMI do not exceed $2-3 \%$; thus the full range presented here corresponds to a long-term drying of the soil, whereas the full range of $D$ can be explored short-term. Thus, on a diurnal scale, subsidence is as important as soil moisture.

As discussed earlier, increasing subsidence (e.g. moving from point $\mathrm{C}$ to point $\mathrm{H}$ ) directly reduces the maximum $\mathrm{ABL}$ height (from 1250 to $825 \mathrm{~m}$ ) and thus causes the atmosphere to become warmer and moister at the end of the day. Increasing soil moisture (e.g. moving from point $\mathrm{D}$ to point C) stimulates evapotranspiration and carbon exchange and generates a cooler, wetter atmosphere at the end of the day. As the figure shows, a simultaneous change of SMI and $D$ (e.g. when we move from the lower-right corner to the upperleft corner of Fig. 8) leads to a $3.5 \mathrm{~K}$ increase in the daytime maximum atmospheric temperature and a $0.5 \mathrm{~g} \mathrm{~kg}^{-1} \mathrm{de}-$ crease in the daytime average atmospheric humidity. These atmospheric conditions, together with the lower availability of soil moisture ( $-20 \%$ SMI), enhance the 14:00 UTC iWUE by $130 \mu \mathrm{mol}_{\mathrm{CO}_{2}} \mathrm{~mol}_{\mathrm{H}_{2} \mathrm{O}}{ }^{-1}$ and reduce the 14:00 UTC 


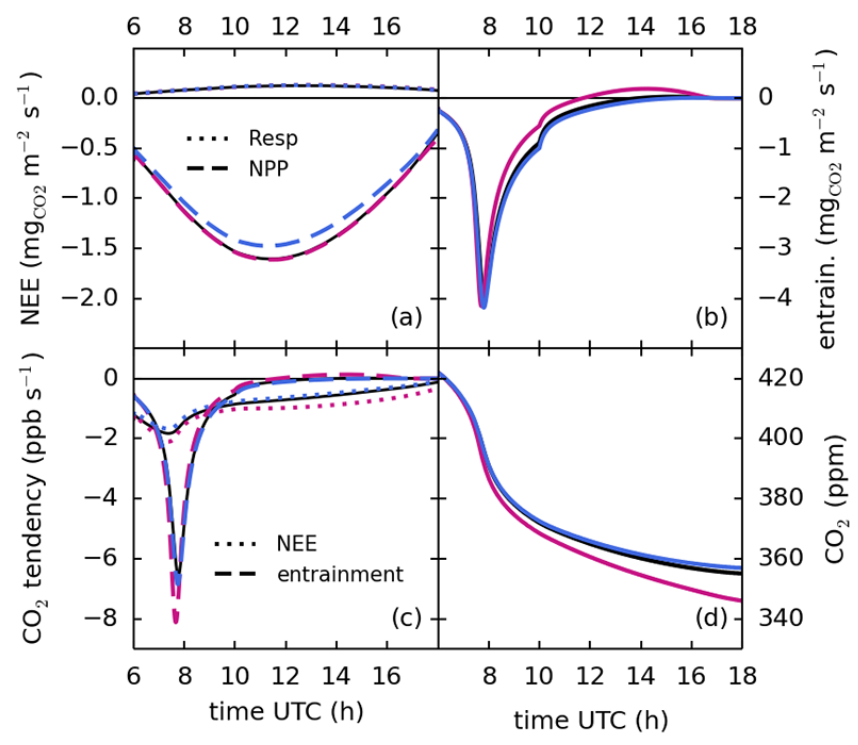

\begin{tabular}{lllll}
- & control & & high subsidence & $-5 \% \mathrm{smi}$ \\
\hline
\end{tabular}

Figure 9. Contributions of the surface and entrainment fluxes to the atmospheric $\mathrm{CO}_{2}$ budget. Net photosynthesis (NPP) and soil respiration (Resp) combine at the surface to form NEE, while the entrainment of $\mathrm{CO}_{2}$ takes place at the top of the boundary layer. All these fluxes are negative when $\mathrm{CO}_{2}$ is being removed from the boundary layer. The $\mathrm{CO}_{2}$ tendencies, which determine the daytime diurnal cycle of $\mathrm{CO}_{2}$, are obtained by dividing these $\mathrm{CO}_{2}$ fluxes by the instantaneous boundary-layer height.

EF by $14.4 \%$. These results are in accordance with studies that state droughts enhance the plant intrinsic water-use efficiency for carbon exchange (e.g. Maseyk et al., 2011) and switch the partitioning of the surface energy balance towards SH at the expense of LE (e.g. Jongen et al., 2011).

We find in Fig. 8 that the positive feedback of subsidence on soil moisture depletion, discussed earlier, is slightly lessened under a prolonged drought. Figure 8 shows that when we increase subsidence (i.e. when we move along the full range of the $y$ axis), the resulting change in $\mathrm{EF}$ is smaller at SMI $0.40(3.0 \%)$ than at SMI $0.60(4.5 \%)$. This is a direct consequence of having less soil moisture available for evapotranspiration. The positive feedback of subsidence on soil moisture is an extension of the feedback loops on evapotranspiration discussed by van Heerwaarden et al. (2010). Our findings indicate that although the stimulation of EF by subsidence is less important under drought, it still contributes to a faster soil moisture depletion and decrease in crop yield over the days. Moreover, from a carbon cycle perspective it is interesting to analyse in more detail how the atmospheric $\mathrm{CO}_{2}$ budget can be affected by surface and upper-atmosphere modifications.

Figure 9 presents the daytime atmospheric $\mathrm{CO}_{2}$ budget. In Fig. $9 \mathrm{c}$ we see that the boundary-layer $\mathrm{CO}_{2}$ tendency receives equivalent contributions from the surface and from entrain- ment, but their distribution in time differs. The contribution of entrainment to the overall $\mathrm{CO}_{2}$ drawdown $(-32 \mathrm{ppm}$ in the control case) happens in the morning, before 09:00 UTC (i.e. 11:00 LT). On the other hand, the contribution of the surface uptake to the overall $\mathrm{CO}_{2}$ drawdown $(-34 \mathrm{ppm}$ in the control case) is more constant throughout the day. In the high-subsidence case, even though the entrainment of $\mathrm{CO}_{2}-$ depleted air is lower (cf. Fig. 9b) and the NEE is unchanged (cf. Fig. 9a), both the surface and entrainment $\mathrm{CO}_{2}$ tendencies are higher due to the lower boundary-layer volume (see Fig. 6a). This is because the tendencies are inversely proportional to the boundary-layer height in the mixed-layer framework, as shown by Pino et al. (2012). Consequently, the atmospheric $\mathrm{CO}_{2}$ mole fraction is even more reduced in the high-subsidence case ( $-12 \mathrm{ppm}$ at 18:00 UTC relative to the control and soil moisture depletion cases; Fig. 9d). Because the larger $\mathrm{CO}_{2}$ drawdown is caused solely by the reduction in boundary-layer height in the high-subsidence case, it is very important to consider the effect of increased subsidence in high-pressure systems when interpreting measurements of the boundary-layer $\mathrm{CO}_{2}$ mole fraction.

\section{Discussion}

\subsection{On the importance of upper-atmosphere processes}

In our study we compare two coupled models, MXL-A-g and MXL-GECROS, against a complete set of surface and boundary-layer observations. Related to our first research question, we hypothesise that entrainment and subsidence are essential processes which contribute to the determination of the carbon, water and energy budgets of the daytime cropatmosphere system. Our findings indeed confirm our hypothesis: we show that entrainment and subsidence have a nonnegligible impact on the daytime surface fluxes (iWUE and $\mathrm{EF}$ ) as well as the atmospheric quantities (temperature, humidity and $\mathrm{CO}_{2}$ mole fraction).

Previous studies have often put emphasis on surface processes. They have shown the importance of calculating correct surface fluxes of heat, water and $\mathrm{CO}_{2}$, to improve numerical weather predictions (e.g. Boussetta et al., 2013; Moreira et al., 2013; Smallman et al., 2013; Hong et al., 2009), atmospheric $\mathrm{CO}_{2}$ modelling (e.g. Corbin et al., 2010; Schuh et al., 2010; Tolk et al., 2009) and crop yield forecast (e.g. de Wit and Van Diepen, 2007). Studies involving two-way coupled models like ours (e.g. Santanello et al., 2013; Tao et al., 2013; Chen and Xie, 2011 and Kohler et al., 2010) have stressed the importance of slowly evolving surface forcings such as soil moisture, vegetation cover and LAI, which drive the surface exchange and strongly impact atmospheric properties like boundary-layer height. Also, interpretations of observed $\mathrm{CO}_{2}$ mole fractions in the $\mathrm{ABL}$ often focus on the role of NEE, typically a large contributor to the atmospheric $\mathrm{CO}_{2}$ budget (Tolk et al., 2009). While we agree that 
these surface processes and drivers are all key to the carbon, water and energy budgets, we have shown that atmospheric processes occurring at the top of the ABL also need to be taken into account.

A few studies have explored the importance of the upperatmosphere processes in the vegetation-atmosphere system. For instance, van Heerwaarden et al. (2009) and Ek and Holtslag (2004) have shown the impact of the ABL-top moisture inversion and the tropospheric temperature lapse rate on surface fluxes, relative humidity at the top of the ABL and the boundary-layer cloud formation. With our sensitivity analysis, we additionally emphasise the importance of another large-scale atmospheric forcing, subsidence, which affects surface fluxes and changes boundary-layer properties like temperature, moisture and $\mathrm{CO}_{2}$ mole fraction.

Our results agree with Canut et al. (2012), Williams et al. (2011), Mcgrath-Spangler and Denning (2010), van Heerwaarden et al. (2009), Casso-Torralba et al. (2008) and VilàGuerau De Arellano et al. (2004), who found ABL growth and entrainment were key controls of the atmospheric $\mathrm{CO}_{2}$ budget at the diurnal scale. However, the observation-based work of Williams et al. (2011) also showed that during longer time periods than the typical 10-day synoptic scale, NEE and large-scale atmospheric transport are the most important contributions to the atmospheric $\mathrm{CO}_{2}$ mole fractions observed in the ABL. Day-to-day variations of ABL growth rates and associated entrainment were less important when interpreting weekly to seasonally averaged $\mathrm{CO}_{2}$ budgets. Here, we show that NEE is impacted by the daytime diurnal coupling of the fluxes of water and heat at the top of the ABL to the crops growing at the surface, possibly at time scales of weeks and longer. This is because crops such as wheat and maize have sensitive periods of less than 2 weeks (e.g. crop germination, anthesis/flowering, ripening) in which crop yield can decline if heat or water stress is applied (Eitzinger et al., 2013; Sánchez et al., 2014). Thus, using a diurnal scale coupled framework to calculate the fluxes of heat, water during those specific periods of crop development could be important even if the direct contribution of entrainment to the $\mathrm{CO}_{2}$ budget becomes smaller at longer time scales. A further investigation of the interactions identified in this work, focusing on the synoptic and seasonal time scales described in Williams et al. (2011), is therefore planned as a follow-up study.

To conclude, we know that the daytime diurnal cycles of heat, water and $\mathrm{CO}_{2}$ are joined in a coupled system: through (a) the canopy stomatal control on $\mathrm{CO}_{2}$ exchange and transpiration, which in turn determines the amount of sensible heat flux in the surface energy balance; and through (b) the large-scale conditions at the top of the boundary layer, which control the daytime boundary-layer development and thus the entrainment and volume dilution of heat, water and $\mathrm{CO}_{2}$. Our findings show these surface and upper-atmosphere controls are of equivalent importance on a diurnal scale for the atmospheric $\mathrm{CO}_{2}$ budget. We recommend using a fully cou- pled land-atmosphere framework to study the daytime atmospheric $\mathrm{CO}_{2}$ budget, as we confirm that the land-induced boundary-layer growth has an important impact due to both volume dilution and $\mathrm{CO}_{2}$ entrainment.

\subsection{On the performance of our models}

Related to our second research question, we hypothesise that the MXL-GECROS model can best reproduce the daytime crop-atmosphere interactions because of the higher level of crop biology detail embedded in the model. However, we show that neither of our models is able to simultaneously reproduce the daytime heat, water and $\mathrm{CO}_{2}$ surface fluxes. MXL-A- $\mathrm{g}_{\mathrm{s}}$ simulates the crop interactions more satisfactorily overall, but it underestimates NEE.

The performance of our two models strongly depends on the sensitivity of the water-stress function to soil moisture. While GECROS only reduces its conductivity, and hence evaporation, close to wilting point, $\mathrm{A}-\mathrm{g}_{\mathrm{s}}$ linearly decreases stomatal conductance from field capacity to wilting point. These are similar water-stress responses as for the CLM3.5 and JULES models shown in Powell et al. (2013). We have confirmed that these differences in water-stress functions are responsible for the overestimation of latent heat by MXLGECROS compared to MXL-A-gs. We conclude, in agreement with Eitzinger et al. (2013) and Powell et al. (2013), that these differences in water-stress implementation could lead to significant differences in simulated crop yield. Studies like that of Verhoef and Egea (2014) can help to validate the water-stress representations of surface models.

The satisfactory performance of our models also depends on the correct initialization of key surface and upperatmosphere variables, as suggested by Sabater et al. (2008). In our study, we lacked measurements of the soil moisture characteristic points (wilting point, field capacity and saturation point). Thus, we estimated them and allowed the MXLA-g $g_{s}$ model to profit from the explicit initialization of soil moisture using the observed Bowen ratio. This was our best estimation possible. We advocate the use of complete sets of observations, including not only soil, vegetation and lower atmosphere but also boundary layer and free troposphere, to evaluate the performance of coupled land-atmosphere models. These proved to be of utmost importance for the validation of the modelled interactions.

For the prospect of going from a diurnal to a seasonal scale study, we regard data assimilation of soil moisture values, as done by e.g. Boussetta et al. (2013); Hong et al. (2009) and de Wit and Van Diepen (2007), as a promising solution. Data assimilation of LAI, as done by Huang et al. (2013), Zhao et al. (2013), Sus et al. (2010) and Jégo et al. (2012), could also help transform our daytime diurnal landsurface scheme A-g into a capable seasonal surface scheme, as previously done within ISBA-A-g (Barbu et al., 2011). Albergel et al. (2010) and Ines et al. (2013) suggest joint assimilation of LAI and soil moisture yields the best results. 
As an alternative, the MXL-A-g model could also benefit from a satisfactory crop phenology module to interactively calculate LAI, like GECROS, as a replacement for LAI data assimilation (e.g. Lokupitiya et al., 2009).

To conclude, we recommend using meteorologicaloriented (surface exchange) models, such as MXL-A-g $\mathrm{g}_{\mathrm{s}}$, for simulations of the daytime crop-atmosphere interactions, as long as the crop is not nitrogen-stressed. However, to simulate longer periods of crop-atmosphere interactions, we recommend adopting a merging strategy to use the distinct advantages of both the generic meteorological-oriented landsurface models (sound surface energy balance) and the specialised crop carbon storage-oriented models (crop phenology, nitrogen stress implementation and prognostic carbon pools). The performance of such models is linked to their correct initialization, which can only be achieved thanks to complete observational data sets. It is also linked to their crop water-stress representation, which conditions the surface energy balance and carbon exchange under shortages of soil moisture.

\section{Conclusions}

In this work, we use a process-based coupled framework to investigate the daytime interactions of $\mathrm{CO}_{2}$, water and heat in the crop-atmosphere system. Our framework strength lies in the relative simplicity of the model that still represents the essential processes of the system. For example, the sensitivity analysis of Fig. 8 and the $\mathrm{CO}_{2}$ budget of Fig. 9 could not easily have been produced using a full meso-scale landatmosphere model. Using it, we are able to study the relevant interactions of the ABL with the surface and to allow a direct comparison to observed ABL and surface variables. Our results show that upper-atmosphere processes and drivers (entrainment and subsidence) are as important as surface processes and drivers (surface fluxes, soil moisture, LAI) to determine the daytime budgets of heat, water and carbon of the crop-atmosphere system. Therefore, ABL dynamics need to be considered when interpreting observations of atmospheric $\mathrm{CO}_{2}$ mole fractions over crops. Using correct estimates of the large-scale forcings are also of key importance. Our modelling framework and its modular design describe these dynamics and allows an extension to other processes, such as the impact of aerosols (Barbaro et al., 2014), clouds (VilàGuerau de Arellano et al., 2012) or ozone on the budgets of carbon, water and heat. Although we have demonstrated that the daytime diurnal scale interactions are well described by a meteorology-oriented coupled model like MXL-A-g $\mathrm{g}_{\mathrm{s}}$, the development of the crop and soil hydraulics at the seasonal scale are likely to be important given the nonlinear response of the coupled system across a wide range of large-scale forcings, as shown in this paper. 


\section{Appendix A}

Table A1. MXL model initial conditions for 4 August 2007.

\begin{tabular}{|c|c|c|}
\hline Variable & Description and unit & Value \\
\hline latt & latitude $\left[{ }^{\circ} \mathrm{N}\right]$ & 51.59 \\
\hline long & longitude $\left[{ }^{\circ} \mathrm{E}\right]$ & 5.38 \\
\hline day & date $[\mathrm{DOY}]$ & 216 \\
\hline $\mathrm{cc}$ & cloud cover $[-]$ & 0.225 \\
\hline$h_{0}$ & initial boundary-layer height $[\mathrm{m}]$ & 230.0 \\
\hline pressure & atmospheric pressure $[\mathrm{hPa}]$ & 1022.0 \\
\hline$D$ & large-scale divergence $\left[\mathrm{s}^{-1}\right]$ & $7 \times 10^{-6}$ \\
\hline$\beta$ & entrainment ratio $[-]$ & 0.2 \\
\hline$\theta_{0}$ & initial potential temperature $[\mathrm{K}]$ & 286.0 \\
\hline$\Delta \theta_{0}$ & initial potential temperature jump $[\mathrm{K}]$ & 5.0 \\
\hline$\gamma_{\theta}$ & potential temperature lapse rate $\left[\mathrm{K} \mathrm{m}^{-1}\right]$ & $8 \times 10^{-3}$ \\
\hline $\operatorname{adv} \theta$ & initial heat advection flux $\left[\mathrm{K} \mathrm{s}^{-1}\right]$ & $3 \times 10^{-4}$ \\
\hline $\operatorname{adv} \theta \operatorname{tim}$ & time of heat advection stop [UTC] & 10:00 \\
\hline$q_{0}$ & initial specific humidity $\left[\mathrm{g} \mathrm{kg}^{-1}\right]$ & 8.5 \\
\hline$\Delta q_{0}$ & initial specific humidity jump $\left[\mathrm{g} \mathrm{kg}^{-1}\right]$ & -1.0 \\
\hline$\gamma_{q}$ & specific humidity lapse rate $\left[\mathrm{g} \mathrm{kg}^{-1} \mathrm{~m}^{-1}\right]$ & -0.0005 \\
\hline $\operatorname{adv} q$ & initial humidity advection flux $\left[\mathrm{g} \mathrm{kg}^{-1} \mathrm{~s}^{-1}\right]$ & $3.5 \times 10^{-4}$ \\
\hline advqtim & time of humidity advection stop [UTC] & 07:30 \\
\hline$c_{0}$ & initial $\mathrm{CO}_{2}$ mole fraction $[\mathrm{ppm}]$ & 422.0 \\
\hline$\Delta c_{0}$ & initial $\mathrm{CO}_{2}$ mole fraction jump [ppm] & -50.0 \\
\hline$\gamma_{c}$ & $\mathrm{CO}_{2}$ mole fraction lapse rate $\left[\mathrm{ppb} \mathrm{m}{ }^{-1}\right]$ & -10.0 \\
\hline$u_{0}$ & initial mixed-layer $\mathrm{u}$-wind speed $\left[\mathrm{m} \mathrm{s}^{-1}\right]$ & 5.0 \\
\hline$u_{\mathrm{g}}$ & geostrophic u-wind speed $\left[\mathrm{m} \mathrm{s}^{-1}\right]$ & 8.0 \\
\hline$\gamma_{u}$ & free troposphere u-wind speed lapse rate $\left[\mathrm{s}^{-1}\right]$ & 0.0 \\
\hline$z_{0, \mathrm{~m}}$ & roughness length for momentum $[\mathrm{m}]$ & 0.15 \\
\hline$z_{0, \mathrm{~h}}$ & roughness length for scalars $[\mathrm{m}]$ & 0.015 \\
\hline
\end{tabular}


Table A2. A-g model initial conditions for 4 August 2007.

\begin{tabular}{|c|c|c|}
\hline Variable & Description and unit & Value \\
\hline albedo & surface albedo [-] & 0.198 \\
\hline LAI & leaf area index $\left[\mathrm{m}^{2} \mathrm{~m}^{-2}\right]$ & 3.5 \\
\hline$f_{\text {veg }}$ & vegetation fraction $[-]$ & 0.97 \\
\hline$r_{\mathrm{s}, \min }$ & minimum resistance for transpiration $\left[\mathrm{s} \mathrm{m}^{-1}\right]$ & 180.0 \\
\hline$r_{\mathrm{s}, \text { soil min }}$ & minimum soil resistance $\left[\mathrm{s} \mathrm{m}^{-1}\right]$ & 50.0 \\
\hline$\Lambda$ & thermal diffusivity skin layer $\left[\mathrm{W} \mathrm{m}^{-2} \mathrm{~K}^{-1}\right.$ ] & 2.5 \\
\hline$g_{\mathrm{D}}$ & VPD correction factor for rs $[-]$ & 0. \\
\hline $\mathrm{CG}_{\text {sat }}$ & saturated heat soil conductivity $\left[\mathrm{K} \mathrm{m}^{-2} \mathrm{~J}^{-1}\right]$ & $3.56 \times 10^{-6}$ \\
\hline$C_{\mathrm{W}}$ & constant water stress correction $[-]$ & 0.0016 \\
\hline$T_{\mathrm{S}}$ & initial surface temperature $[\mathrm{K}]$ & 290.0 \\
\hline$T_{\text {soil }}$ & temperature of top soil layer $[\mathrm{K}]$ & 288.0 \\
\hline$T_{2}$ & temperature of deeper soil layer $[\mathrm{K}]$ & 289.0 \\
\hline$w_{\mathrm{g}}$ & water content top soil layer $\left[\mathrm{cm}^{3} \mathrm{~cm}^{-3}\right]$ & 0.11 \\
\hline$w_{2}$ & water content deep soil layer $\left[\mathrm{cm}^{3} \mathrm{~cm}^{-3}\right]$ & 0.11 \\
\hline$w_{\text {sat }}$ & saturation water content $\left[\mathrm{cm}^{3} \mathrm{~cm}^{-3}\right]$ & 0.36 \\
\hline$w_{\mathrm{fc}}$ & field capacity water content $\left[\mathrm{cm}^{3} \mathrm{~cm}^{-3}\right]$ & 0.15 \\
\hline$w_{\text {wilt }}$ & wilting point water content $\left[\mathrm{cm}^{3} \mathrm{~cm}^{-3}\right]$ & 0.06 \\
\hline$w_{\mathrm{s}, \max }$ & upper reference value soil water $[-]$ & 0.55 \\
\hline$w_{\mathrm{s}, \min }$ & lower reference value soil water $[-]$ & 0.005 \\
\hline$C_{1, \text { sat }}$ & coefficient force term moisture $[-]$ & 0.132 \\
\hline$C_{2, \text { ref }}$ & coefficient restore term moisture $[-]$ & 1.8 \\
\hline$a$ & Clapp and Hornberger retention curve parameter $a[-]$ & 0.219 \\
\hline$b$ & Clapp and Hornberger retention curve parameter $b[-]$ & 4.9 \\
\hline$p$ & Clapp and Hornberger retention curve parameter $c[-]$ & 4. \\
\hline$\Gamma(298 \mathrm{~K})$ & $\mathrm{CO}_{2}$ compensation concentration at $298 \mathrm{~K}_{\left[\mathrm{mg} \mathrm{m}^{-3}\right]}$ & 4.3 \\
\hline$Q_{10} \Gamma$ & percentage of increase in $\Gamma(298 \mathrm{~K})$ with $+10 \mathrm{~K}[-]$ & 1.5 \\
\hline$g_{\mathrm{m}}(298 \mathrm{~K})$ & mesophyll conductance at $298 \mathrm{~K}\left[\mathrm{~mm} \mathrm{~s}^{-1}\right]$ & 17.5 \\
\hline$Q_{10} g_{\mathrm{m}}$ & percentage of increase in $g_{\mathrm{m}}$ with $+10 \mathrm{~K}[-]$ & 2.0 \\
\hline$T_{1} g_{\mathrm{m}}$ & reference temperature $T_{1}$ for $g_{\mathrm{m}}[\mathrm{K}]$ & 286.0 \\
\hline$T_{2} g_{\mathrm{m}}$ & reference temperature $T_{2}$ for $g_{\mathrm{m}}[\mathrm{K}]$ & 309.0 \\
\hline$A_{\mathrm{m}, \max }(298 \mathrm{~K})$ & $\mathrm{CO}_{2}$ maximal primary productivity at $298 \mathrm{~K}\left[\mathrm{mg} \mathrm{m}^{-2} \mathrm{~s}^{-1}\right]$ & 1.7 \\
\hline$Q_{10} A_{\mathrm{m}}$ & percentage of increase in $A_{\mathrm{m}, \max }$ with $+10 \mathrm{~K}[-]$ & 2.0 \\
\hline$T_{1} A_{\mathrm{m}}$ & reference temperature $T_{1}$ for $A_{\mathrm{m}, \max }[\mathrm{K}]$ & 286.0 \\
\hline$T_{2} A_{\mathrm{m}}$ & reference temperature $T_{2}$ for $A_{\mathrm{m}, \max }[\mathrm{K}]$ & 311.0 \\
\hline$f_{0}$ & maximum value $C_{\text {frac }}[-]$ & 0.85 \\
\hline$a_{\mathrm{d}}$ & regression coefficient for $C_{\mathrm{frac}}\left[\mathrm{kPa}^{-1}\right]$ & 0.15 \\
\hline$\alpha_{0}$ & initial low light conditions $\left[\mathrm{mg} \mathrm{J}^{-1}\right]$ & 0.014 \\
\hline$K_{\mathrm{X}}$ & extinction coefficient for PAR $[-]$ & 0.7 \\
\hline$g_{\min }$ & cuticular minimum conductance $\left[\mathrm{m} \mathrm{s}^{-1}\right]$ & $2.5 \times 10^{-4}$ \\
\hline$R_{10}$ & respiration at $10^{\circ} \mathrm{C}\left[\mathrm{mgCO}_{2} \mathrm{~m}^{-2} \mathrm{~s}^{-1}\right]$ & 0.03 \\
\hline$E_{\text {act }_{0}}$ & activation energy $\left[\mathrm{kJ} \mathrm{kmol}^{-1}\right]$ & $5.33 \times 10^{4}$ \\
\hline
\end{tabular}


Table A3. GECROS model initial conditions for 4 August 2007. See Yin and van Laar (2005) and Sinclair and de Wit (1975) for the rest of the maize average genotype parameters.

\begin{tabular}{|c|c|c|}
\hline Variable & Description and unit & Value \\
\hline SLP & short day crop & yes \\
\hline DETER & determinate crop & yes \\
\hline $\mathrm{C} 3 \mathrm{C} 4$ & C4 crop & yes \\
\hline LODGE & lodging allowed & no \\
\hline LEGUME & legume crop & no \\
\hline NPL & plant density [plant $\mathrm{m}^{-2}$ ] & 9.1 \\
\hline EG & efficiency of germination [\%] & 3.6783 \\
\hline HTMX & maximum plant height $[\mathrm{m}]$ & 2.8 \\
\hline BLD & leaf angle $[\mathrm{deg}]$ & 50. \\
\hline SEEDW & seed weight $[\mathrm{g}]$ & 0.5 \\
\hline MTDV & minimal thermal days for vegetative phase $[\mathrm{d}]$ & 41.0 \\
\hline MTDR & minimal thermal days for reproductive phase $[\mathrm{d}]$ & 15.7 \\
\hline PSEN & photoperiod sensitivity of phenological development $\left[\mathrm{h}^{-1}\right]$ & 0. \\
\hline $\mathrm{TM}$ & development stage when transition from CB to CX is fastest [-] & 1.5 \\
\hline CX & factor for initial $\mathrm{N}$ concentration of seed fill [-] & 1. \\
\hline СB & factor for final $\mathrm{N}$ concentration of seed fill $[-]$ & 1. \\
\hline PNLS & fraction of dead leaf $\mathrm{N}$ incorporated into soil litter [-] & 1. \\
\hline CLAY & percentage of clay in the soil [\%] & 7. \\
\hline WCMAX & soil water content at maximum holding capacity $\left[\mathrm{m}^{3} \mathrm{~m}^{-3}\right]$ & 0.36 \\
\hline WCFC & soil water content at field capacity $\left[\mathrm{m}^{3} \mathrm{~m}^{-3}\right]$ & 0.15 \\
\hline WCMIN & minimum soil water content $\left[\mathrm{m}^{3} \mathrm{~m}^{-3}\right]$ & 0.06 \\
\hline RPMR0 & decomposition rate for resistant plant material $\left[\mathrm{yr}^{-1}\right]$ & 0.3 \\
\hline DPMR0 & decomposition rate for decomposable plant material $\left[\mathrm{yr}^{-1}\right]$ & 10. \\
\hline HUMR & decomposition rate for humidified organic matter $\left[\mathrm{yr}^{-1}\right]$ & 0.02 \\
\hline BIOR & decomposition rate for microbial in the soil $\left[\mathrm{yr}^{-1}\right]$ & 0.66 \\
\hline DRPM & ratio DPM / RPM of added plant material [-] & 1.44 \\
\hline RA & residual ammonium- $\mathrm{N}$ in the soil $\left[\mathrm{g} \mathrm{N} \mathrm{m}^{-2}\right]$ & 1. \\
\hline FBIOC & $\begin{array}{l}\text { fraction of initial microbial biomass in the soil } \\
\text { in the initial total soil organic carbon (TOC) [-] }\end{array}$ & 0.03 \\
\hline BHC & $\begin{array}{l}\text { initial soil microbial biomass }+ \text { humified soil organic } \\
\text { matter }\left[\mathrm{g} \mathrm{C} \mathrm{m}^{-2}\right]\end{array}$ & 3500. \\
\hline TOC & total organic $\mathrm{C}$ in the soil $\left[\mathrm{g} \mathrm{Cm}^{-2}\right]$ & 7193. \\
\hline $\mathrm{RN}$ & residual nitrate- $\mathrm{N}$ in the soil $\left[\mathrm{g} \mathrm{N} \mathrm{m}^{-2}\right]$ & 1. \\
\hline MULTF & multiplication factor for initial soil water status $[-]$ & 1. \\
\hline ТСТ & time constant for soil temperature dynamics [d] & 4. \\
\hline RSS & $\begin{array}{l}\text { soil resistance for water vapour transfer, equivalent } \\
\text { to leaf stomatal resistance }\left[\mathrm{s} \mathrm{m}^{-1}\right]\end{array}$ & 80. \\
\hline SD1 & thickness of upper evaporative soil layer $[\mathrm{cm}]$ & 5. \\
\hline TCP & time constant for some soil dynamic processes [d] & 1. \\
\hline FNA1 & ammonium- $\mathrm{N}$ added in the 1 st fertiliser application $\left[\mathrm{g} \mathrm{Nm}^{-2} \mathrm{~d}^{-1}\right]$ & 10. \\
\hline FNA1T & day number at which the 1 st ammonium-N dose is applied [DOY] & 1. \\
\hline
\end{tabular}


Acknowledgements. This research was funded by the Netherlands Organisation for Scientific Research through VIDI grant no. 864.08.012 and by the China Exchange Program of the Dutch Royal Academy of Research (KNAW) through travel grant no. 12CDP006. The authors acknowledge Xinyou Yin (Wageningen University) and Kees Rappoldt (EcoCurves BV) for their expert help with the GECROS model. We also thank Henk Klein Baltink (KNMI) and Fred Bosveld (KNMI) for providing the Cabauw data, Eduardo Barbaro (Wageningen University) for his help with the radiation formulation, and Denica Bozhinova (Wageningen University) for her help with programming a part of the analysis code.

Edited by: N. Zeng

\section{References}

Ahmadov, R., Gerbig, C., Kretschmer, R., Koerner, S., Neininger, B., Dolman, A. J., and Sarrat, C.: Mesoscale covariance of transport and $\mathrm{CO}_{2}$ fluxes: Evidence from observations and simulations using the WRF-VPRM coupled atmosphere-biosphere model, J. Geophys. Res., 112, D22107, doi:10.1029/2007JD008552, 2007.

Albergel, C., Calvet, J.-C., Mahfouf, J.-F., Rüdiger, C., Barbu, A. L., Lafont, S., Roujean, J.-L., Walker, J. P., Crapeau, M., and Wigneron, J.-P.: Monitoring of water and carbon fluxes using a land data assimilation system: a case study for southwestern France, Hydrol. Earth Syst. Sci., 14, 1109-1124, doi:10.5194/hess-14-1109-2010, 2010.

Aubinet, M., Vesala, T., and Papale, D. (Eds.): Eddy Covariance: A Practical Guide to Measurement and Data Analysis, Springer, Dordrecht, the Netherlands, 2012.

Ball, J. T.: An analysis of stomatal conductance, Ph.D. thesis, Stanford University, Stanford, CA, 1988.

Barbaro, E. and Vilà-Guerau De Arellano, J. and Ouwersloot, H. G. and Schröter, J. and Donovan, D. P. and Krol, M. C.: Aerosols in the convective boundary layer: Shortwave radiation effects on the coupled land atmosphere system, J. Geophys. Res.-Atmos., 119, 5845-5863, 2014.

Barbu, A. L., Calvet, J.-C., Mahfouf, J.-F., Albergel, C., and Lafont, S.: Assimilation of Soil Wetness Index and Leaf Area Index into the ISBA-A-gs land surface model: grassland case study, Biogeosciences, 8, 1971-1986, doi:10.5194/bg-8-19712011, 2011.

Beljaars, A. C. M. and Bosveld, F. C.: Cabauw data for the validation of land surface parameterization schemes, Journal of Climate, 10, 1172-1193, 1997.

Bert, F. E., Laciana, C. E., Podestá, G. P., Satorre, E. H., and Menéndez, A. N.: Sensitivity of CERES-Maize simulated yields to uncertainty in soil properties and daily solar radiation, Agr. Syst., 94, 141-150, 2007.

Betts, A. K.: Non-precipitating cumulus convection and its parameterization, Q. J. Roy. Meteor. Soc., 99, 178-196, 1973.

Betts, A. K.: Understanding hydrometeorology using global models, B. Am. Meteorol. Soc., 85, 1673-1688, 2004.

Betts, R. A.: Integrated approaches to climate-crop modelling: needs and challenges, Philos. T. Roy. Soc. B, 360, 2049-2065, 2005.
Bonan, G. B.: Forests and climate change: forcings, feedbacks, and the climate benefits of forests, Science, 320, 1444-1449, 2008.

Boussetta, S., Balsamo, G., Beljaars, A., Panareda, A. A., Calvet, J. C., Jacobs, C., Van Den Hurk, B., Viterbo, P., Lafont, S., Dutra, E., Jarlan, L., Balzarolo, M., Papale, D., and Van Der Werf, G.: Natural land carbon dioxide exchanges in the ECMWF integrated forecasting system: implementation and offline validation, J. Geophys. Res.-Atmos., 118, 5923-5946, 2013.

Brienen, R., Wanek, W., and Hietz, P.: Stable carbon isotopes in tree rings indicate improved water use efficiency and drought responses of a tropical dry forest tree species, Trees, 25, 103-113, 2011.

Canut, G., Couvreux, F., Lothon, M., Pino, D., and Saïd, F.: Observations and large-eddy simulations of entrainment in the sheared sahelian boundary layer, Bound.-Lay. Meteorol., 142, 79-101, 2012.

Carson, D. J.: The development of a dry inversion-capped convectively unstable boundary layer, Q. J. Roy. Meteor. Soc., 99, 450467, 1973.

Casso-Torralba, P., Vilà-Guerau de Arellano, J., Bosveld, F., Soler, M. R., Vermeulen, A., Werner, C., and Moors, E.: Diurnal and vertical variability of the sensible heat and carbon dioxide budgets in the atmospheric surface layer, J. Geophys. Res., 113, D12119, doi:10.1029/2007JD009583, 2008.

Challinor, A. J., Ewert, F., Arnold, S., Simelton, E., and Fraser, E.: Crops and climate change: progress, trends, and challenges in simulating impacts and informing adaptation, J. Exp. Bot., 60, 2775-2789, 2009.

Chen, F. and Xie, Z.: Effects of crop growth and development on regional climate: a case study over East Asian monsoon area, Clim. Dynam., 38, 2291-2305, 2011.

Ciais, P., Wattenbach, M., Vuichard, N., Smith, P., Piao, S. L., Don, A., Luyssaert, S., Janssens, I. A., Bondeau, A., Dechow, R., Leip, A., Smith, P. C., Beer, C., van der Werf, G., Gervois, S., van Oost, K., Tomelleri, E., Freibauer, A., and Schulze, E. D.: The European carbon balance. Part 2: Croplands, Glob. Change Biol., 16, 1409-1428, 2010.

Collatz, G. J., Ball, J. T., Grivet, C., and Berry, J. A.: Physiological and environmental regulation of stomatal conductance, photosynthesis and transpiration: a model that includes a laminar boundary layer, Agr. Forest Meteorol., 54, 107-136, 1991.

Corbin, K. D., Denning, A. S., Lokupitiya, E. Y., Schuh, A. E., Miles, N. L., Davis, K. J., Richardson, S., and Baker, I. T.: Assessing the impact of crops on regional $\mathrm{CO}_{2}$ fluxes and atmospheric concentrations, Tellus B, 62, 521-532, 2010.

Cowan, I. R.: Stomatal behaviour and environment, Adv. Bot. Res., 4, 117-228, 1978.

Cox, P. M., Pearson, D., Booth, B. B., Friedlingstein, P., Huntingford, C., Jones, C. D., and Luke, C. M.: Sensitivity of tropical carbon to climate change constrained by carbon dioxide variability, Nature, 494, 341-344, 2013.

Daly, E., Porporato, A., and Rodriguez-Iturbe, I.: Coupled dynamics of photosynthesis, transpiration, and soil water balance. Part II: Stochastic analysis and ecohydrological significance, J. Hydrometeorol., 5, 559-566, 2004.

de Bruin, H. A. R. and Holtslag, A. A. M.: A simple parameterization of the surface fluxes of sensible and latent-heat during 
daytime compared with the Penman-Monteith concept, J. Appl. Meteorol., 21, 1610-1621, 1982.

De Pury, D. G. G. and Farquhar, G. D.: Simple scaling of photosynthesis from leaves to canopies without the errors of big-leaf models, Plant Cell Environ., 20, 537-557, 1997.

de Wit, A. J. W. and Van Diepen, C. A.: Crop model data assimilation with the Ensemble Kalman filter for improving regional crop yield forecasts, Agr. Forest Meteorol., 146, 38-56, 2007.

Eitzinger, J., Formayer, H., Thaler, S., Trnka, M., Zdenek, Z., and Alexandrov, V.: Aspects on results and uncertainties of climate change impact simulation studies for agricultural crop production in Europe, Bodenkultur, 59, 131-147, 2008.

Eitzinger, J., Thaler, S., Schmid, E., Strauss, F., Ferrise, R., Moriondo, M., Bindi, M., Palosuo, T., Rötter, R., Kersebaum, K. C., Olesen, J. E., Patil, R. H., Şaylan, L., Çaldağ, B., and Çaylak, O.: Sensitivities of crop models to extreme weather conditions during flowering period demonstrated for maize and winter wheat in Austria, J. Agr. Sci., 151, 813-835, 2013.

Ek, M. B. and Holtslag, A. A. M.: Influence of soil moisture on boundary layer cloud development, J. Hydrometeorol., 5, 86-99, 2004.

FAOSTAT 2011 land-use statistics: The land-use resources subdomain covers land area, temporary crops area and permanent crops area, FAOSTAT online database, available at: http: //faostat3.fao.org/faostat-gateway/go/to/download/R/RL/E (last access: 3 March 2014), 2014.

Farquhar, G. D., O'leary, M. H., and Berry, J. A.: On the relationship between carbon isotope discrimination and the intercellular carbon dioxide concentration in leaves, Aust. J. of Plant Physiol., 9, 121-137, 1982.

Foken, T.: The energy balance closure problem: An overview, Ecological Applications, 18, 1351-1367, 2008.

Foken, T., Mauder, M., Liebethal, C., Wimmer, F., Beyrich, F., Leps, J. P., Raasch, S., DeBruin, H. A. R., Meijninger, W. M. L., and Bange, J.: Energy balance closure for the LITFASS-2003 experiment, Theor. Appl. Climatol., 101, 149-160, 2010.

Friedlingstein, P., Cox, P., Betts, R., Bopp, L., Von Bloh, W., Brovkin, V., Cadule, P., Doney, S., Eby, M., Fung, I., Bala, G., John, J., Jones, C., Joos, F., Kato, T., Kawamiya, M., Knorr, W., Lindsay, K., Matthews, H. D., Raddatz, T., Rayner, P., Reick, C., Roeckner, E., Schnitzler, K. G., Schnur, R., Strassmann, K., Weaver, A. J., Yoshikawa, C., and Zeng, N.: Climate-carbon cycle feedback analysis: results from the $\mathrm{C}^{4} \mathrm{MIP}$ model intercomparison, J. Climate, 19, 3337-3353, 2006.

Gervois, S., Ciais, P., de Noblet-Ducoudré, N., Brisson, N., Vuichard, N., and Viovy, N.: Carbon and water balance of European croplands throughout the 20th century, Global Biogeochem. Cy., 22, GB2022, doi:10.1029/2007GB003018, 2008.

Hong, S., Lakshmi, V., Small, E. E., Chen, F., Tewari, M., and Manning, K. W.: Effects of vegetation and soil moisture on the simulated land surface processes from the coupled WRF/Noah model, J. Geophys. Res.-Atmos., 114, D18118, doi:10.1029/2008JD011249, 2009.

Huang, Y., Zhu, Y., Li, W. L., Cao, W. X., and Tian, Y. C.: Assimilating remotely sensed information with the wheatgrow model based on the ensemble square root filter for improving regional wheat yield forecasts, Plant Prod. Sci., 16, 352-364, 2013.

Ines, A. V. M., Das, N. N., Hansen, J. W., and Njoku, E. G.: Assimilation of remotely sensed soil moisture and vegetation with a crop simulation model for maize yield prediction, Remote Sens. Environ., 138, 149-164, 2013.

Jacobs, C. M. J., van den Hurk, B. M. M., and de Bruin, H. A. R.: Stomatal behaviour and photosynthetic rate of unstressed grapevines in semi-arid conditions, Agr. Forest Meteorol., 80, 111-134, 1996.

Jacobs, C. M. J., Jacobs, A. F. G., Bosveld, F. C., Hendriks, D. M. D., Hensen, A., Kroon, P. S., Moors, E. J., Nol, L., Schrier-Uijl, A., and Veenendaal, E. M.: Variability of annual $\mathrm{CO}_{2}$ exchange from Dutch grasslands, Biogeosciences, 4, 803816,2007 , http://www.biogeosciences.net/4/803/2007/.

Jans, W. W. P., Jacobs, C. M. J., Kruijt, B., Elbers, J. A., Barendse, S., and Moors, E. J.: Carbon exchange of a maize (Zea mays L.) crop: influence of phenology, Agr. Ecosyst. Environ., 139, 316-324, 2010.

Jarvis, P. G.: The Interpretation of the Variations in Leaf Water Potential and Stomatal Conductance Found in Canopies in the Field, Philos. T. Roy. Soc. B, 273, 593-610, 1976.

Jégo, G., Pattey, E., and Liu, J.: Using Leaf Area Index, retrieved from optical imagery, in the STICS crop model for predicting yield and biomass of field crops, Field Crop. Res., 131, 63-74, 2012.

Jongen, M., Pereira, J. S., Aires, L. M. I. and Pio, C. A.: The effects of drought and timing of precipitation on the inter-annual variation in ecosystem-atmosphere exchange in a Mediterranean grassland, Agr. Forest Meteorol., 151, 595-606, 2011.

Keenan, T. F., Hollinger, D. Y., Bohrer, G., Dragoni, D., Munger, J. W., Schmid, H. P., and Richardson, A. D.: Increase in forest water-use efficiency as atmospheric carbon dioxide concentrations rise, Nature, 499, 324-327, 2013.

Kohler, M., Kalthoff, N., and Kottmeier, C.: The impact of soil moisture modifications on CBL characteristics in West Africa: a case-study from the AMMA campaign, Q. J. Roy. Meteor. Soc., 136, 442-455, 2010.

Krinner, G., Viovy, N., De Noblet-Ducoudré, N., Ogée, J., Polcher, J., Friedlingstein, P., Ciais, P., Sitch, S., and Prentice, I. C.: A dynamic global vegetation model for studies of the coupled atmosphere-biosphere system, Global Biogeochem. Cy., 19, 1-33, 2005.

Lehuger, S., Gabrielle, B., Cellier, P., Loubet, B., Roche, R., Béziat, P., Ceschia, E., and Wattenbach, M.: Predicting the net carbon exchanges of crop rotations in Europe with an agroecosystem model, Agr. Ecosyst. Environ., 139, 384-395, 2010.

Leuning, R., Kelliher, F. M., Pury, D. G. G., and Schulze, E. D.: Leaf nitrogen, photosynthesis, conductance and transpiration: scaling from leaves to canopies, Plant Cell Environ., 18, 1183-1200, 1995.

Lilly, D. K.: Models of cloud-topped mixed layers under a strong inversion, Q. J. Roy. Meteor. Soc., 94, 292-309, 1968.

Lobell, D. B., Schlenker, W., and Costa-Roberts, J.: Climate trends and global crop production since 1980, Science, 333, 616-620, 2011.

Lokupitiya, E., Denning, S., Paustian, K., Baker, I., Schaefer, K., Verma, S., Meyers, T., Bernacchi, C. J., Suyker, A., and Fischer, M.: Incorporation of crop phenology in Simple Biosphere Model (SiBcrop) to improve land-atmosphere carbon exchanges from croplands, Biogeosciences, 6, 969-986, 2009, http://www.biogeosciences.net/6/969/2009/. 
Maseyk, K., Hemming, D., Angert, A., Leavitt, S. W. and Yakir, D.: Increase in water-use efficiency and underlying processes in pine forests across a precipitation gradient in the dry Mediterranean region over the past 30 years, Oecologia, 167, 573-585, 2011.

Mcgrath-Spangler, E. L. and Denning, A. S.: Impact of entrainment from overshooting thermals on land-atmosphere interactions during summer 1999, Tellus B, 62, 441-454, 2010.

Meyers, T. P. and Hollinger, S. E.: An assessment of storage terms in the surface energy balance of maize and soybean, Agr. Forest Meteorol., 125, 105-115, 2004.

Moreira, D. S., Freitas, S. R., Bonatti, J. P., Mercado, L. M., Rosário, N. M. É., Longo, K. M., Miller, J. B., Gloor, M., and Gatti, L. V.: Coupling between the JULES land-surface scheme and the CCATT-BRAMS atmospheric chemistry model (JULESCCATT-BRAMS1.0): applications to numerical weather forecasting and the $\mathrm{CO}_{2}$ budget in South America, Geosci. Model Dev., 6, 1243-1259, 2013.

Pino, D., Vilà-Guerau de Arellano, J., Peters, W., Schröter, J., van Heerwaarden, C. C., and Krol, M. C.: A conceptual framework to quantify the influence of convective boundary layer development on carbon dioxide mixing ratios, Atmos. Chem. Phys., 12, 2969-2985, doi:10.5194/acp-12-2969-2012, 2012.

Powell, T. L., Galbraith, D. R., Christoffersen, B. O., Harper, A., Imbuzeiro, H. M. A., Rowland, L., Almeida, S., Brando, P. M., da Costa, A. C. L., Costa, M. H., Levine, N. M., Malhi, Y., Saleska, S. R., Sotta, E., Williams, M., Meir, P., and Moorcroft, P. R.: Confronting model predictions of carbon fluxes with measurements of Amazon forests subjected to experimental drought, The New Phytol., 200, 350-365, 2013.

Ronda, R. J., De Bruin, H., and Holtslag, A.: Representation of the canopy conductance in modeling the surface energy budget for low vegetation, J. Appl. Meteorol., 40, 1431-1444, 2001.

Sabater, J. M., Rüdiger, C., Calvet, J. C., Fritz, N., Jarlan, L., and Kerr, Y.: Joint assimilation of surface soil moisture and LAI observations into a land surface model, Agr. Forest Meteorol., 148, 1362-1373, 2008.

Sánchez, B., Rasmussen, A., and Porter, J. R.: Temperatures and the growth and development of maize and rice: a review, Glob. Change Biol., 20, 408-417, 2014.

Santanello Jr., J. A., Peters-Lidard, C. D., Kennedy, A., and Kumar, S. V.: Diagnosing the nature of land-atmosphere coupling: a case study of dry/wet extremes in the U. S. Southern Great Plains, J. Hydrometeorol., 14, 3-24, 2013.

Schuh, A. E., Denning, A. S., Corbin, K. D., Baker, I. T., Uliasz, M., Parazoo, N., Andrews, A. E., and Worthy, D. E. J.: A regional high-resolution carbon flux inversion of North America for 2004, Biogeosciences, 7, 1625-1644, doi:10.5194/bg-71625-2010, 2010.

Silva, L. C. R. and Horwath, W. R.: Explaining global increases in water use efficiency: why have we overestimated responses to rising atmospheric $\mathrm{CO}_{2}$ in natural forest ecosystems?, PLoS ONE, 8, e53089, doi:10.1371/journal.pone.0053089, 2013.

Sinclair, T. S. and de Wit, C. T.: Photosynthate and nitrogen requirements for seed production by various crops, Science, 189, 565-567, 1975.

Sitch, S., Smith, B., Prentice, I. C., Arneth, A., Bondeau, A., Cramer, W., Kaplan, J. O., Levis, S., Lucht, W., and Sykes, M. T.: Evaluation of ecosystem dynamics, plant geography and terres- trial carbon cycling in the LPJ dynamic global vegetation model, Glob. Change Biol., 9, 161-185, 2003.

Sitch, S., Huntingford, C., Gedney, N., Levy, P. E., Lomas, M., Piao, S. L., Betts, R., Ciais, P., Cox, P., Friedlingstein, P., Jones, C. D., Prentice, I. C., and Woodward, F. I.: Evaluation of the terrestrial carbon cycle, future plant geography and climatecarbon cycle feedbacks using five Dynamic Global Vegetation Models (DGVMs), Glob. Change Biol., 14, 2015-2039, 2008.

Smallman, T. L., Moncrieff, J. B., and Williams, M.: WRFv3.2SPAv2: development and validation of a coupled ecosystematmosphere model, scaling from surface fluxes of $\mathrm{CO}_{2}$ and energy to atmospheric profiles, Geosci. Model Dev., 6, 1079-1093, 2013.

Smith, P. C., De Noblet-Ducoudré, N., Ciais, P., Peylin, P., Viovy, N., Meurdesoif, Y., and Bondeau, A.: European-wide simulations of croplands using an improved terrestrial biosphere model: Phenology and productivity, J. Geophys. Res., 115, G01014, doi:10.1029/2008JG000800, 2010.

Sus, O., Williams, M., Bernhofer, C., Béziat, P., Buchmann, N., Ceschia, E., Doherty, R., Eugster, W., Grünwald, T., Kutsch, W., Smith, P., and Wattenbach, M.: A linked carbon cycle and crop developmental model: Description and evaluation against measurements of carbon fluxes and carbon stocks at several European agricultural sites, Agr. Ecosyst. Environ., 139, 402-418, 2010.

Tao, Z., Santanello, J. A., Chin, M., Zhou, S., Tan, Q., Kemp, E. M., and Peters-Lidard, C. D.: Effect of land cover on atmospheric processes and air quality over the continental United States a NASA Unified WRF (NU-WRF) model study, Atmos. Chem. Phys., 13, 6207-6226, doi:10.5194/acp-13-6207-2013, 2013.

Tennekes, H.: A model for the dynamics of the inversion above a convective boundary layer, J. Atmos. Sci., 30, 558-567, 1973.

Teuling, A. J., Seneviratne, S. I., Stöckli, R., Reichstein, M., Moors, E., Ciais, P., Luyssaert, S., van den Hurk, B., Ammann, C., Bernhofer, C., Dellwik, E., Gianelle, D., Gielen, B., Grünwald, T., Klumpp, K., Montagnani, L., Moureaux, C., Sottocornola, M., and Wohlfhart, G.: Contrasting response of European forest and grassland energy exchange to heatwaves, Nat. Geosci., 3, 722-727, doi:10.1038/ngeo950, 2010.

Tolk, L. F., Peters, W., Meesters, A. G. C. A., Groenendijk, M., Vermeulen, A. T., Steeneveld, G. J., and Dolman, A. J.: Modelling regional scale surface fluxes, meteorology and $\mathrm{CO}_{2}$ mixing ratios for the Cabauw tower in the Netherlands, Biogeosciences, 6 , 2265-2280, 2009, http://www.biogeosciences.net/6/2265/2009/.

Twine, T. E., Kustas, W. P., Norman, J. M., Cook, D. R., Houser, P. R., Meyers, T. P., Prueger, J. H., Starks, P. J., and Wesely, M. L.: Correcting eddy-covariance flux underestimates over a grassland, Agr. Forest Meteorol., 103, 279-300, 2000.

van Heerwaarden, C. C., Vilà-Guerau de Arellano, J., Moene, A. F., and Holtslag, A. A. M.: Interactions between dry-air entrainment, surface evaporation and convective boundary-layer development, Q. J. Roy. Meteor. Soc., 135, 1277-1291, 2009.

van Heerwaarden, C. C., Vilà-Guerau De Arellano, J., Gounou, A., Guichard, F. and Couvreux, F.: Understanding the Daily Cycle of Evapotranspiration: A Method to Quantify the Influence of Forcings and Feedbacks, J. Hydrometeorol., 11, 1405-1422, 2010a.

Verhoef, A. and Egea, G.: Modeling plant transpiration under limited soil water: Comparison of different plant and soil hydraulic parameterizations and preliminary implications for their 
use in land surface models, Agr. Forest Meteorol., 191, 22-32, doi:10.1016/j.agrformet.2014.02.009, 2014.

Vilà-Guerau De Arellano, J., Gioli, B., Miglietta, F., Jonker, H. J. J., Baltink, H. K., Hutjes, R. W. A., and Holtslag, A. A. M.: Entrainment process of carbon dioxide in the atmospheric boundary layer, J. Geophys. Res.-Atmos., 109, D18110, doi:10.1029/2004JD004725, 2004.

Vilà-Guerau de Arellano, J., van den Dries, K., and Pino, D.: On inferring isoprene emission surface flux from atmospheric boundary layer concentration measurements, Atmos. Chem. Phys., 9, 3629-3640, doi:10.5194/acp-9-3629-2009, 2009.

Vilà-Guerau de Arellano, J., van Heerwaarden, C. C., and Lelieveld, J.: Modelled suppression of boundary-layer clouds by plants in a $\mathrm{CO}_{2}$-rich atmosphere, Nat. Geosci., 5, 1-4, 2012.

Williams, I. N., Riley, W. J., Torn, M. S., Berry, J. A., and Biraud, S. C.: Using boundary layer equilibrium to reduce uncertainties in transport models and $\mathrm{CO}_{2}$ flux inversions, Atmos. Chem. Phys., 11, 9631-9641, doi:10.5194/acp-11-9631-2011, 2011.
Yin, X. and van Laar, H. H.: Crop Systems Dynamics: An Ecophysiological Simulation Model for Genotype-by-Environment Interactions, Wageningen Academic Publishers, Wageningen, the Netherlands, 2005.

Zhao, W. and Qualls, R. J.: Modeling of long-wave and net radiation energy distribution within a homogeneous plant canopy via multiple scattering processes, Water Resour. Res., 42, W08436, doi:10.1029/2005WR004581, 2006.

Zhao, Y., Chen, S., and Shen, S.: Assimilating remote sensing information with crop model using Ensemble Kalman Filter for improving LAI monitoring and yield estimation, Ecol. Model., 270, 30-42, 2013. 